Review

\title{
Graphene-Based Semiconductor Heterostructures for Photodetectors
}

\author{
Dong Hee Shin (1) and Suk-Ho Choi * \\ Department of Applied Physics and Institute of Natural Sciences, Kyung Hee University, Yongin 17104, Korea; \\ sdh0105@hanmail.net \\ * Correspondence: sukho@khu.ac.kr; Tel.: +82-31-201-2418
}

Received: 29 May 2018; Accepted: 11 July 2018; Published: 13 July 2018

\begin{abstract}
Graphene transparent conductive electrodes are highly attractive for photodetector (PD) applications due to their excellent electrical and optical properties. The emergence of graphene/semiconductor hybrid heterostructures provides a platform useful for fabricating high-performance optoelectronic devices, thereby overcoming the inherent limitations of graphene. Here, we review the studies of PDs based on graphene/semiconductor hybrid heterostructures, including device physics/design, performance, and process technologies for the optimization of PDs. In the last section, existing technologies and future challenges for PD applications of graphene/semiconductor hybrid heterostructures are discussed.
\end{abstract}

Keywords: graphene; photodetector; transparent conductive electrode; hybrid heterostructure

\section{Introduction}

A photodetector (PD) is a device for detecting light, the underlying mechanism is conversion of light to an electrical signal called a photocurrent (PC). PDs are used in a wide range of academic and industrial fields, including image sensing, optical communications, environmental monitoring, and chemical/biological sensing [1-3]. In PDs, usually made of inorganic or organic semiconducting materials, incident photons are absorbed and subsequently electron-hole pairs are generated, thereby producing PC. PDs are classified mainly as photodiodes, photoconductors, and phototransistors. Despite increasing reliability of the fabrication processes, their high cost/complexity and the large driving voltage of PDs have limited the diffusibility, compatibility, and versatility of PDs for broad applications and new technologies. In order to solve these problems, many studies have focused on how to develop simple processes for high-performance PDs, especially by using transparent conductive electrodes (TCEs) such as metal nanowires (NWs) [4,5], conducting polymers [6], carbon nanotubes $[7,8]$, and graphene instead of metal or transparent conducting oxide electrodes. Among them, graphene is recognized as one of the next-generation TCEs, as explained below. Firstly, the extremely high carrier mobility of graphene enables ultrafast conversion of photons or plasmons to electrical signal, which is highly desirable for high-speed photodetection $[9,10]$. Secondly, the tunable electrical and optical properties of graphene, such as carrier densities, band alignments, and polarities, via chemical or electrostatic doping offer great flexibility for optimizing the performance of graphene-based optoelectronic devices [11,12].

A wide variety of optoelectronic devices based on graphene are still being studied, and some of them have already reached a level of competitiveness comparable to conventional semiconductor devices [13,14]. However, single-layer graphene has low light absorbance (only 2.3\%) in the ultraviolet (UV) to near infrared (NIR) region and short light-matter interaction length, unfavorable for light harvesting applications $[15,16]$. In addition, the ultra-short lifetime of excitons in pure graphene resulting from its gapless nature also leads to fast carrier recombination, which limits the efficient 
production of PC or photovoltage [17,18]. Graphene itself can act as an absorber in ultrafast and ultra-broadband detectors, but the sensitivity of graphene-based detectors is relatively low, not suitable for most practical applications.

The emergence of the graphene/SiC interface in 2009 [19] as the prototype of graphene/semiconductor heterostructure has attracted much attention due to the expected synergistic properties of the two materials. Afterwards, the rapid development of graphene transfer techniques has led to a wide variety of unique designs for the functionality of the device geometry based on graphene/semiconductor hybrid heterostructures. Unlike other detector structures, the best feature of graphene/semiconductor junctions is the adjustable Schottky barrier height, useful not only for understanding the interface transport mechanism, but also for adjusting the device functionalities. Recent studies have shown that graphene/semiconductor interfaces/heterojunctions are efficient for generation, separation, and transmission of photocarriers, thereby exhibiting new features in their optoelectronic applications [20-23]. A broad review of recent developments in this area will not only offer new insight into light-matter interactions, but it will also help inspire future nontraditional next-generation detector designs.

Chemical vapor deposition (CVD)-grown graphene was first employed in graphene/Si heterojunctions, resulting in 65\% external quantum efficiency (EQE) [24], which served as the prototype for the subsequent intensive studies on the graphene TCEs-based various kinds of semiconductor hybrid heterojunctions for high-efficiency PDs [24-100]. Here, we review recent progress in the development of graphene TCEs-based semiconductor hybrid heterojunction PDs. Despite the frequent use of mechanical cleavage and chemical exfoliation for graphene, we focus on CVD-grown graphene for PDs, most popular for practical device applications at the moment. First, we briefly explain key figure-of-merit parameters that are used to characterize PDs. In the main section, we discuss the issues related to physics/design, processing technologies, and performance of PDs fabricated by using various kinds of materials. Finally, we summarize the technologies reported so far and the significance/outlook for guiding continuing development of the graphene-TCEs-based PDs.

\section{Operation Mechanisms}

Graphene/semiconductor hybrid heterostructures can be formed by directly combining graphene with one-, two-, and three-dimensional semiconductors through relatively simple manufacturing processes. When graphene and a semiconductor material form a junction, charge transfer occurs until the Fermi energy levels of the two materials coincide because their work functions mismatch. Meanwhile, the free charge region inside the semiconductor near the interface is depleted by the charge transfer, resulting in the formation of the built-in electric field. In case of graphene/n-type semiconductor junction, the immobile positive charge formed by the depletion of electrons bends the semiconductor band near the interface upward. More details are given in previous reports [101, 102]. In the equilibrium state where the Fermi energy levels are aligned, the discontinuity of the allowed energy states of the two materials creates an energy barrier $\left(\Phi_{\mathrm{B}}\right)$ to prevent the electrons from flowing from the semiconductor to the graphene. Depending on the energy of the radiation $(E)=h v$ ( $h=$ Planck's constant and $v=$ photon frequency), PC is generated based on two main mechanisms. (1) When $\Phi_{\mathrm{B}}<h v<$ semiconductor band gap $\left(E_{g}\right)$, the electrons are excited from the graphene and are injected into the semiconductor; (2) When $h v>E_{g}$, the electron-hole pairs are generated in the depletion layer of the semiconductor. The PDs are operated based on the photovoltaic or photogating effect depending on their device configurations.

\subsection{Photovoltaic Effect}

The PD can be operated in a photovoltaic mode (=zero bias). The heterostructures generally exhibit rectifying behaviors, i.e., nonlinear current density-voltage $(J-V)$ characteristics under dark. A PD operating in this mode is named as a photodiode, whose linearity, detectivity, and sensitivity are maximized due to the lowest dark current. In contrast, the responsivity $(R)$ is usually low due 
to the lack of internal gain. The PD can be also operated in reverse bias (photoconductive mode), where the built-in external electromagnetic field enhances the separation efficiency of the electron-hole pairs, thereby reducing the response time due to the shortening of the passage time and the decrease of the diode capacity. The photovoltaic mode is more suitable for precise photodetection with the photoconductive mode being better suited for high-speed applications.

\subsection{Photogating Effect}

Photogating effects occur in the heterostructures-based phototransistors. The operating mechanism of the phototransistors is as follows. Once electron-hole pairs are generated in semiconductors, one type of carrier is transferred to the graphene, and the opposite-type carrier is trapped in the semiconductor. The trapped charges act as a local gate, thereby effectively modulating the Fermi level of graphene through capacitive coupling. This induces more carriers and consequently modulates the electrical conductance. In addition, the transferred free carriers circulate many times in the graphene channel within their lifetime, which contributes to higher photoconduction gain. The gain is expressed as gain = lifetime/transit, where transit is the transit time of the photogenerated carriers through the graphene channel. Shorter transit time and longer lifetime should be obtained to achieve higher gain. Nevertheless, the lifetime of the photocarrier is determined by the response time, which is directly related to the carrier recombination process. Thus, a high gain will extend the response time. A phototransistor can show much higher $R$ than a photodiode, but the response speed of the former is slower than that of the latter. Due to the effective gate field of the trapped carriers, the photogate effect generally appears as a horizontal shift of the source-drain current-gate voltage $\left(I_{S D^{-}} V_{g}\right)$ curve of the graphene transistor upon illumination. In addition, the direction of the curve shift represents the polarity of the captured carriers, and the photogate effect can induce positive or negative PC by $V_{g}$.

\section{Figure of Merits for Characterizing Photodetectors}

\subsection{Responsivity $(R)$}

$R$ is defined as the ratio of PC to incident light power, which indicates how efficiently a PD responds to an optical signal, as expressed by the equation $R=I_{p h} / L_{\text {light }}$, in a unit of A/W, where $I_{p h}$ is the PC and $L_{\text {light }}$ is the incident-light power. $R$ is proportional to EQE of a PD, meaning the conversion rate from photons to electrons/holes. Therefore, EQE is related to $R$ based on the following equation:

$$
R=E Q E \times \lambda q / h c
$$

where $\lambda$ is the incident-light wavelength, $q$ is the absolute value of electron charge, $h$ is the Planck constant, and $c$ is the speed of light.

\subsection{Detectivity $\left(D^{*}\right)$}

$D^{*}$ is the weakest level of light which can be detected by the device, and is determined by $R$ and noise of a PD. $D^{*}$ is given by $D^{*}=(A \cdot \Delta f)^{1 / 2} \times R / i_{n}$. Where $A$ is the effective area of a PD, $\Delta f$ is the electrical bandwidth, and $i_{n}$ is the noise current. The performance of $D^{*}$ is limited by three kinds of noise such as dark current (DC), Johnson noise, and thermal fluctuation noise [103]. By assuming the shot noise as the dominant contribution, $D^{*}$ is expressed by the formula: $D^{*}=R /\left(2 q J_{d}\right)^{1 / 2}$ where $J_{d}$ is the DC density.

\subsection{Noise Equivalent Power (NEP)}

Noise should be kept as low as possible because it determines minimum detectable signal. There are several kinds of noises such as thermal noise, shot noise, and flicker noise, composing the total noise. In this context, NEP is an associated figure of merit, and is defined as the optical power that 
yields a single signal-to-noise ratio for a given bandwidth, in a unit of $\mathrm{W} \cdot \mathrm{Hz}^{-1 / 2}$. NEP also represents minimum detectable power and is calculated by the following equation.

$$
N E P=i_{n} / R=(A \cdot \Delta f)^{1 / 2} / D^{*}
$$

\subsection{Linear Dynamic Range (LDR)}

LDR describes an illumination intensity range within which the current response of a PD scales linearly with the light intensity. LDR is given by the equation: LDR $=20 \log \left(J_{p h}{ }^{*} / J_{d}\right)$ where $J_{p h}{ }^{*}$ is the PC density measured at a light intensity of $1 \mathrm{~mW} \cdot \mathrm{cm}^{-2}$. For practical applications, it is desirable to have a large LDR for a PD capable of detecting both weak and strong light.

\subsection{Response Speed}

The response of a PD to an optical signal is characterized by the rise/fall times, defined as the times at $10 / 90 \%$ of the maximum PC, respectively, which are strongly related to the charge transport/collection and the bandwidth of the photoresponse.

In the following sections, the PD characteristics are detailed for various kinds of graphene $\mathrm{TCE} /$ semiconductor heterostructures, whose major figure of merit parameters are summarized in Table 1.

\section{Graphene/Silicon}

\subsection{Doping of Graphene}

The built-in electric potential at the graphene/Si interface is determined by the difference between the work functions of graphene and Si when no bias is applied. Pristine graphene forms a low Schottky barrier with $\mathrm{Si}$ due to the relatively-small work function $(4.5 \mathrm{eV})$, and the pristine graphene/Si junction exhibits a large series resistance due to the relatively large sheet resistance of pristine graphene. These issues should be overcome to enhance the performance of the graphene/Si PDs. Chemical doping is a very efficient approach for increasing the work function and conductivity of graphene, resulting in the increase of the Schottky barrier and the reduction of the series resistance. The electrons and holes are then less recombined, thereby improving the performance of the PDs.

\subsection{Graphene/Silicon Wafer}

In the last decade, graphene/Si heterostructures have been studied for optical detection based on a powerful photovoltaic effect. In these structures, light absorption takes place in $\mathrm{Si}$ whilst graphene acts as an electrode for efficient carrier transport and collection. Early studies have shown that the graphene/Si Schottky junctions, introduced in 2013 (Figure 1a) [24], were very sensitive to the illumination in broadband wavelengths [24-26], thereby showing $R$ and NEP greater than $10^{7} \mathrm{~V} / \mathrm{W}$ and $1 \mathrm{pW} \cdot \mathrm{Hz}^{-1 / 2}$, respectively, in optical voltage mode, as shown in Figure $1 \mathrm{~b}, \mathrm{c}$. The Fermi level of graphene was controlled by 1-pyrenecarboxylic acid doping, allowing smooth transport/collection of high-density holes photogenerated in $\mathrm{Si}$ under illumination, resulting in $0.435 \mathrm{~A} / \mathrm{W} R, 65 \% \mathrm{EQE}$, and $7.69 \times 10^{9} \mathrm{~cm} \cdot \mathrm{Hz}^{1 / 2} \cdot \mathrm{W}^{-1}$ Jones $D^{*}$.

Table 1. Figure-of-merit parameters of semiconductor heterostructure photodetectors with graphene TCEs, reported until recently.

\begin{tabular}{|c|c|c|c|c|c|c|}
\hline Device Structure & PC/DC & $\begin{array}{c}R\left(\mathrm{~A} \cdot \mathrm{W}^{-1}\right) / \\
\text { Gain/EQE }(\%)\end{array}$ & $D^{*}\left(\mathrm{~cm} \cdot \mathrm{Hz}^{1 / 2} \cdot \mathrm{W}^{-1}\right)$ & LDR (dB) & $\begin{array}{l}\text { Recovery } \\
\text { Time (ms) }\end{array}$ & Ref. \\
\hline TPA-doped tri-layer graphene/Si & $10^{4}$ & $\begin{array}{c}\text { EQE: } 65 \\
\text { @ 550-800 nm }\end{array}$ & $2.1 \times 10^{8}$ & - & 3 & [24] \\
\hline Graphene/Si & - & $\begin{array}{c}R: 0.28 \\
@ 1550 \mathrm{~nm}\end{array}$ & - & - & - & [25] \\
\hline
\end{tabular}


Table 1. Cont.

\begin{tabular}{|c|c|c|c|c|c|c|}
\hline Device Structure & PC/DC & $\begin{array}{c}R\left(\mathrm{~A} \cdot \mathrm{W}^{-1}\right) / \\
\text { Gain/EQE (\%) }\end{array}$ & $D^{*}\left(\mathrm{~cm} \cdot \mathrm{Hz}^{1 / 2} \cdot \mathrm{W}^{-1}\right)$ & LDR (dB) & $\begin{array}{c}\text { Recovery } \\
\text { Time (ms) }\end{array}$ & Ref. \\
\hline $\mathrm{Al}_{2} \mathrm{O}_{3} /$ graphene/Si & $10^{6}$ & $\begin{array}{l}\text { EQE: } 86.8 \\
\text { @ } 200 \mathrm{~nm}\end{array}$ & $1.6 \times 10^{13}$ & 127 & $5 \times 10^{-6}$ & {$[28]$} \\
\hline Pt NPs/graphene/Si & - & $\begin{array}{l}\text { EQE: } 80 \\
\text { @ } 790 \mathrm{~nm}\end{array}$ & $7.5 \times 10^{10}$ & - & $7.8 \times 10^{-7}$ & [29] \\
\hline $\mathrm{MoO}_{3} /$ graphene/Si & - & $\begin{array}{l}\text { EQE: } 80 \\
\text { @ } 550 \mathrm{~nm}\end{array}$ & $5.4 \times 10^{12}$ & - & - & [30] \\
\hline Graphene/thin $\mathrm{SiO}_{2} / \mathrm{Si}$ & $10^{7}$ & $\begin{array}{l}\text { EQE: } 60 \\
\text { @ } 650 \mathrm{~nm}\end{array}$ & $4.2 \times 10^{12}$ & 90 & $7.5 \times 10^{-1}$ & [31] \\
\hline Graphene $/ \mathrm{SiO}_{2} / \mathrm{Si}$ & - & $\begin{array}{c}R: 3 \\
\text { @ } 545 \mathrm{~nm}\end{array}$ & $3.5 \times 10^{12}$ & - & - & [32] \\
\hline Graphene nanowalls/Si & - & $\begin{array}{l}\text { EQE: } 79.6 \\
@ 810 \mathrm{~nm}\end{array}$ & $5.9 \times 10^{13}$ & 105 & $4 \times 10^{-2}$ & [34] \\
\hline Graphene/porous Si & - & $\begin{array}{l}\text { EQE: } 60 \\
\text { @ } 500 \mathrm{~nm}\end{array}$ & - & - & $3 \times 10^{-3}$ & [35] \\
\hline AuNPs/graphene/ $\mathrm{CH}_{3}-\mathrm{SiNW}$ & $10^{6}$ & $\begin{array}{l}R: 1.5 \\
\text { @ } 950 \mathrm{~nm}\end{array}$ & $2.5 \times 10^{14}$ & - & $9.6 \times 10^{-2}$ & [36] \\
\hline $\begin{array}{c}\mathrm{AuCl}_{3} \text {-doped } \\
\text { graphene/SQDs:SiO }\end{array}$ & $10^{1}$ & $\begin{array}{l}\text { EQE: } 72 \\
\text { @ } 600 \mathrm{~nm} \\
\end{array}$ & $8.9 \times 10^{8}$ & 73 & $1.6 \times 10^{-2}$ & {$[38]$} \\
\hline TFSA-doped graphene/SQDs:SiO & - & $\begin{array}{l}\text { EQE: } 84 \\
\text { @ } 600 \mathrm{~nm}\end{array}$ & $1.1 \times 10^{10}$ & 92 & $7 \times 10^{-3}$ & [39] \\
\hline SQDs/graphene/Si & - & $\begin{array}{l}\text { EQE: } 80 \\
\text { @ } 500 \mathrm{~nm}\end{array}$ & $7.4 \times 10^{9}$ & - & $2.5 \times 10^{-5}$ & [40] \\
\hline B-doped SQDs/graphene/Si & - & $\begin{array}{l}\text { EQE: } 10^{12} \\
\text { @ } 532 \mathrm{~nm}\end{array}$ & $\sim 10^{13}$ & - & $9 \times 10^{3}$ & [41] \\
\hline Graphene/GaN & $10^{5}$ & $\begin{array}{l}R: 0.001 \\
\text { @ } 350 \mathrm{~nm}\end{array}$ & - & - & - & [42] \\
\hline Graphene/GaN NWs & - & $\begin{array}{l}R: 0.25 \\
@ 357 \mathrm{~nm}\end{array}$ & - & - & - & [43] \\
\hline MLG/GaAs & $10^{4}$ & $\begin{array}{l}R: 0.173 \\
@ 850 \mathrm{~nm}\end{array}$ & $1.8 \times 10^{11}$ & - & $1.2 \times 10^{-1}$ & [44] \\
\hline Bilayer-graphene $/ \mathrm{Al}_{2} \mathrm{O}_{3} / \mathrm{GaAs}$ & $10^{5}$ & $\begin{array}{l}R: 0.005 \\
@ 850 \mathrm{~nm}\end{array}$ & $2.9 \times 10^{11}$ & - & $4.8 \times 10^{-2}$ & [46] \\
\hline $\mathrm{ZnO} Q \mathrm{QDs} /$ graphene/ $\mathrm{SiO}_{2} / \mathrm{Si}$ & - & $\begin{array}{l}\text { Gain: } 10^{7} \\
\text { @ } 445 \mathrm{~nm}\end{array}$ & - & - & $10^{3}$ & [49] \\
\hline Graphene/ZnO Nanorod & - & $\begin{array}{l}R: 3 \times 10^{5} \\
@ 365 \mathrm{~nm}\end{array}$ & - & - & $6.6 \times 10^{4}$ & {$[50]$} \\
\hline Fewlayer-graphene/ZnO NWs & - & $\begin{array}{l}\text { R: } 6.7 \times 10^{4} \\
\text { @ } 365 \mathrm{~nm}\end{array}$ & $10^{11}$ & - & $1.2 \times 10^{4}$ & [54] \\
\hline ZnOQDs/graphene/SAM/ $\mathrm{SiO}_{2} / \mathrm{Si}$ & $10^{7}$ & $\begin{array}{l}R: 3 \times 10^{9} \\
@ 335 \mathrm{~nm}\end{array}$ & $5.1 \times 10^{13}$ & - & $2.3 \times 10^{3}$ & [55] \\
\hline $\begin{array}{c}\text { ZnO QDs } \\
\text { core/Zn(Ac)shell/graphene/ } \mathrm{SiO}_{2} / \mathrm{Si}\end{array}$ & 1.7 & $\begin{array}{c}R: 10^{9} \\
@ 330 \mathrm{~nm}\end{array}$ & $1 \times 10^{14}$ & - & $8.5 \times 10^{4}$ & [56] \\
\hline Graphene/ZnO NR arrays & $10^{2}$ & $\begin{array}{l}R: 113 \\
\text { @ } 365 \mathrm{~nm}\end{array}$ & - & - & 3.6 & [57] \\
\hline Graphene/h-BN/ZnO & - & $\begin{array}{l}R: 1350 \\
\text { @ } 365 \mathrm{~nm}\end{array}$ & - & - & $5.2 \times 10^{3}$ & [58] \\
\hline Graphene/ZnO/Si & - & $\begin{array}{l}\text { EQE: } 80 \\
\text { @ } 390 \mathrm{~nm}\end{array}$ & $3.9 \times 10^{13}$ & - & $5.4 \times 10^{-1}$ & {$[61]$} \\
\hline Graphene/ZnO & 12.1 & $\begin{array}{l}R: 3 \times 10^{4} \\
@ 365 \mathrm{~nm}\end{array}$ & $4.3 \times 10^{14}$ & - & $2.2 \times 10^{4}$ & [62] \\
\hline Graphene.ZnO NWs/graphene & - & $\begin{array}{l}R: 22.7 \\
\text { @ } 370 \mathrm{~nm}\end{array}$ & - & - & $4.7 \times 10^{2}$ & [64] \\
\hline $\mathrm{ZrO}$ quantum dots/graphene & & $\begin{array}{c}R: 22 \\
\text { @ } 266 \mathrm{~nm}\end{array}$ & & & $10^{4}$ & {$[68]$} \\
\hline $\mathrm{MLG} / \mathrm{Ga}_{2} \mathrm{O}_{3}$ & & $\begin{array}{c}R: 39.3 \\
\text { @ } 254 \mathrm{~nm}\end{array}$ & $5.9 \times 10^{13}$ & & $2.2 \times 10^{5}$ & [69] \\
\hline Graphene $/ \mathrm{Ga}_{2} \mathrm{O}_{3} /$ graphene & $10^{3}$ & $\begin{array}{c}R: 10 \\
@ 254 \mathrm{~nm}\end{array}$ & & & $9.6 \times 10^{2}$ & [70] \\
\hline
\end{tabular}


Table 1. Cont.

\begin{tabular}{|c|c|c|c|c|c|c|}
\hline Device Structure & PC/DC & $\begin{array}{c}R\left(\mathrm{~A} \cdot \mathrm{W}^{-1}\right) / \\
\text { Gain/EQE }(\%)\end{array}$ & $D^{*}\left(\mathrm{~cm} \cdot \mathrm{Hz}^{1 / 2} \cdot \mathrm{W}^{-1}\right)$ & LDR (dB) & $\begin{array}{l}\text { Recovery } \\
\text { Time (ms) }\end{array}$ & Ref. \\
\hline P3HT/graphene/PZT & - & $\begin{array}{c}G: 10^{3} \\
@ 325 \mathrm{~nm}\end{array}$ & - & - & $1.6 \times 10^{3}$ & [71] \\
\hline Pentacene/graphene/cPVP $/ \mathrm{Al}_{2} \mathrm{O}_{3} / \mathrm{A}$ & AuNPs & $\begin{array}{c}R: 700 \\
@ 520 \mathrm{~nm}\end{array}$ & $10^{13}$ & - & - & [72] \\
\hline C8-BTBT/graphene/SiO $2 / \mathrm{Si}$ & - & $\begin{array}{c}R: 10^{5} \\
\text { @ } 355 \mathrm{~nm}\end{array}$ & - & - & $8.3 \times 10^{2}$ & [73] \\
\hline $\mathrm{MAPbI}_{3} /$ graphene $/ \mathrm{SiO}_{2} / \mathrm{Si}$ & - & $\begin{array}{c}R: 180 \\
@ 520 \mathrm{~nm}\end{array}$ & $10^{9}$ & - & $5.4 \times 10^{2}$ & [74] \\
\hline $\mathrm{MAPbI}_{3}$ /graphene/ $\mathrm{Al}_{2} \mathrm{O}_{3} / \mathrm{PVP}$ & - & $\begin{array}{c}R: 115 \\
\text { @ } 515 \mathrm{~nm}\end{array}$ & $3 \times 10^{12}$ & - & $5.3 \times 10^{3}$ & [75] \\
\hline $\mathrm{MAPbI}_{3} /$ graphene/AuNPs $/ \mathrm{SiO}_{2} / \mathrm{Si}$ & - & $\begin{array}{c}R: 10^{3} \\
@ 532 \mathrm{~nm}\end{array}$ & - & - & $1.7 \times 10^{4}$ & [76] \\
\hline $\mathrm{PMMA} / \mathrm{MAPbI}_{3} / \mathrm{ODTS} / \mathrm{SiO}_{2} / \mathrm{Si}$ & - & $\begin{array}{c}R: 10^{7} \\
\text { @ } 532 \mathrm{~nm}\end{array}$ & $2 \times 10^{15}$ & & $9 \times 10^{2}$ & [77] \\
\hline $\mathrm{MAPbI}_{3-\mathrm{x}} \mathrm{Cl}_{\mathrm{x}} / \mathrm{P} 3 \mathrm{HT} / \mathrm{SiO}_{2} / \mathrm{Si}$ & - & $\begin{array}{c}R: 10^{9} \\
\text { @ } 598 \mathrm{~nm}\end{array}$ & - & - & $10^{4}$ & [78] \\
\hline $\mathrm{MAPbI}_{3} \mathrm{NWs} /$ graphene $/ \mathrm{SiO}_{2} / \mathrm{Si}$ & - & $\begin{array}{c}R: 10^{6} \\
@ 633 \mathrm{~nm}\end{array}$ & - & - & $7.5 \times 10^{4}$ & [79] \\
\hline $\mathrm{CsPbBr}_{3-\mathrm{x}} \mathrm{I}_{\mathrm{x}} /$ graphene $/ \mathrm{SiO}_{2} / \mathrm{Si}$ & - & $\begin{array}{c}R: 10^{9} \\
\text { @ } 405 \mathrm{~nm}\end{array}$ & $2 \times 10^{16}$ & - & $3.6 \times 10^{3}$ & [80] \\
\hline Graphite QDs/graphene/ $\mathrm{SiO}_{2} / \mathrm{Si}$ & - & $\begin{array}{c}R: 10^{7} \\
@ 325 \mathrm{~nm}\end{array}$ & - & - & - & [81] \\
\hline graphene QDs/graphene & - & $\begin{array}{c}G: 10^{3} \\
@ 325 \mathrm{~nm}\end{array}$ & - & - & - & [82] \\
\hline Graphene QD/graphene/PZT & - & $\begin{array}{c}R: 10^{9} \\
\text { @ } 325 \mathrm{~nm}\end{array}$ & - & - & $1.5 \times 10^{4}$ & [83] \\
\hline $\begin{array}{l}\text { Graphene/graphene } \\
\text { QDs/graphene }\end{array}$ & $10^{3}$ & $\begin{array}{c}R: 0.5 \\
@ 800 \mathrm{~nm}\end{array}$ & $10^{11}$ & 95 & $2 \times 10^{-3}$ & [84] \\
\hline $\begin{array}{c}\text { Graphene/Si NPs-graphene } \\
\text { QDs/graphene }\end{array}$ & 3 & $\begin{array}{c}\text { R: } 0.31 \\
@ 532 \mathrm{~nm}\end{array}$ & - & - & - & [86] \\
\hline Graphene/SWNT/SiO $/ \mathrm{Si}$ & - & $\begin{array}{c}R: 10^{2} \\
@ 650 \mathrm{~nm}\end{array}$ & - & - & $10^{-1}$ & [87] \\
\hline Graphene/CNT/SiO $/ \mathrm{Si}$ & $10^{2}$ & $\begin{array}{c}R: 0.21 \\
@ 980 \mathrm{~nm}\end{array}$ & $4.87 \times 10^{10}$ & 60 & $7.8 \times 10^{-1}$ & [88] \\
\hline InSe/graphene/ $\mathrm{SiO}_{2} / \mathrm{Si}$ & - & $\begin{array}{c}R: 10^{5} \\
\text { @ } 633 \mathrm{~nm}\end{array}$ & - & - & $10^{1}$ & [89] \\
\hline Graphene/WS $/$ graphene & 54 & $\begin{array}{c}R: 3.5 \\
@ 532 \mathrm{~nm}\end{array}$ & $10^{11}$ & - & - & [90] \\
\hline Graphene/MoTe 2 /graphene & $10^{5}$ & $\begin{array}{c}R: 87 \\
@ 473 \text { nm }\end{array}$ & $10^{12}$ & - & $2.3 \times 10^{1}$ & [91] \\
\hline Graphene $/ \mathrm{MoS}_{2} / \mathrm{SiO}_{2} / \mathrm{Si}$ & - & $\begin{array}{c}R: 107 \\
@ 532 \mathrm{~nm}\end{array}$ & - & - & - & [92] \\
\hline Graphene/WS 2 /graphene & - & $\begin{array}{l}\text { EQE: } 30 \\
@ 633 \text { nm }\end{array}$ & - & - & - & [93] \\
\hline Graphene/MoS $/$ graphene & - & $\begin{array}{l}\text { EQE: } 27 \\
@ 514 \text { nm }\end{array}$ & - & - & $5 \times 10^{-2}$ & [94] \\
\hline Graphene/WS 2 /graphene & - & $\begin{array}{l}\text { EQE: } 7.3 \\
\text { @ } 759 \text { nm }\end{array}$ & - & - & $5.5 \times 10^{-9}$ & [95] \\
\hline Graphene $/ \mathrm{MoS}_{2} / \mathrm{SiO}_{2} / \mathrm{Si}$ & - & $\begin{array}{c}R: 1.26 \\
@ 1440 \mathrm{~nm}\end{array}$ & $4.2 \times 10^{10}$ & - & - & [96] \\
\hline $\mathrm{MoS}_{2} / \mathrm{h}-\mathrm{BN} / \mathrm{Graphene}$ & 6.6 & $\begin{array}{c}R: 0.3 \\
@ 532 \mathrm{~nm}\end{array}$ & - & - & $1.1 \times 10^{4}$ & [97] \\
\hline $\mathrm{WS}_{2} /$ graphene $/ \mathrm{SiO}_{2} / \mathrm{Si}$ & $10^{4}$ & $\begin{array}{c}R: 350 \\
@ 532 \mathrm{~nm}\end{array}$ & $10^{13}$ & - & $3 \times 10^{-2}$ & [99] \\
\hline $\mathrm{WSe}_{2} /$ graphene $/ \mathrm{MoS}_{2}$ & - & $\begin{array}{c}R: 10^{4} / 10^{-1} \\
\text { @ } 400 / 2400 \mathrm{~nm}\end{array}$ & - & - & $\begin{array}{c}5 \times 10^{-2} / 3 \\
\times 10^{-2}\end{array}$ & [100] \\
\hline
\end{tabular}



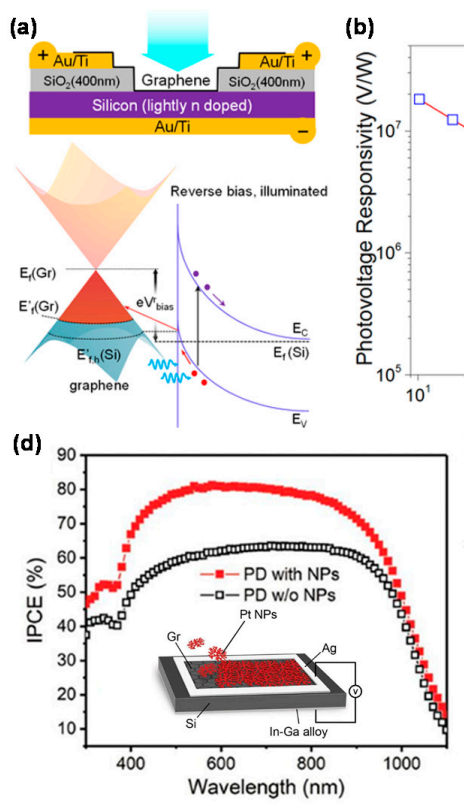

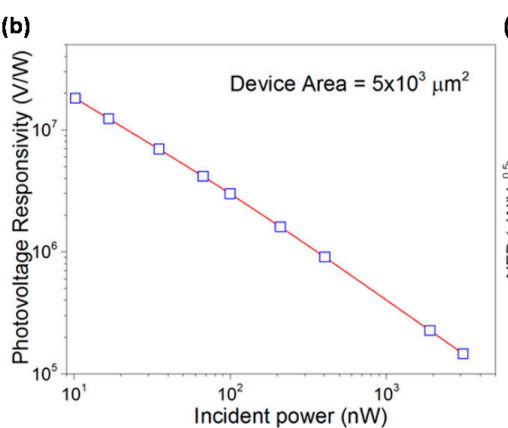

(e)

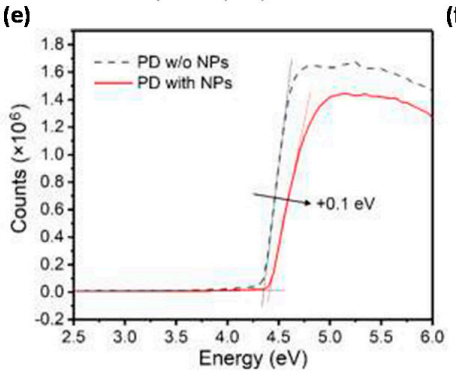

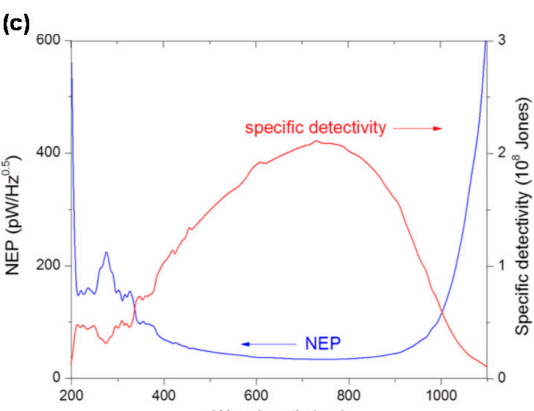

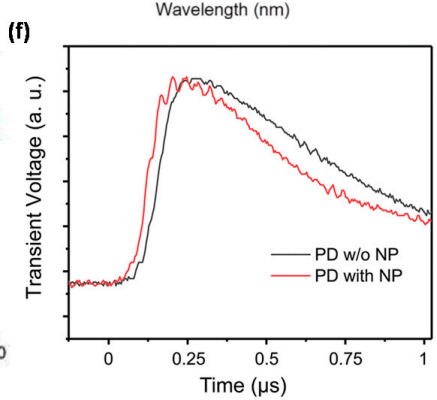

Figure 1. (a) Schematic diagram and band structure of a typical monolayer graphene/Si heterojunction device. Application of a reverse bias raises $E_{f}$ (graphene: $\mathrm{Gr}$ ) and opens up a large number of accessible states that can be occupied by photoexcited holes injected from Si under illumination; (b) Variation of the voltage responsivity as a function of incident power, obtained under the open-circuit condition. At the lowest powers, the voltage responsivity exceeds $10^{7} \mathrm{~V} / \mathrm{W}$; (c) Spectral dependence of the NEP and specific detectivity $\left(D^{*}\right)$ in the photocurrent mode. Reproduced with permission for Figure 1a-c from 2013 Nano Letter [24]; (d) Incident photon conversion efficiency (IPCE) spectra of graphene-Si PDs with and without fractal Pt NPs. The inset shows schematic diagram of a Si-graphene PD with fractal Pt NPs; (e) Ultraviolet photoelectron spectroscopy data of graphene-Si PDs with and without fractal Pt NPs, showing the effect of physical doping on the Fermi level; (f) Transient photovoltage characteristics of graphene-Si PDs with and without fractal Pt NPs under $532 \mathrm{~nm}$ pulse laser. Reproduced with permission for Figure 1d-f from 2017 Advanced Optical Materials [29].

The gapless and semi-metallic properties of graphene are very promising for its application for broadband photodetection from microwave to UV wavelengths. Graphene/Si Schottky PDs are also very efficient in fast carrier separation due to the presence of the built-in electric field without suffering from a sharp reduction in the lifetime of photocarriers under $1550 \mathrm{~nm}$ illumination [25], thereby showing an $R$ of $0.28 \mathrm{~A} / \mathrm{W}$, corresponding to an internal quantum efficiency of $10 \%$, much higher than a typical Schottky junction ( 1\%). Usually, the $\mathrm{R}$ in the $\mathrm{UV}$ region is at least 1-2 times lower than that in the visible-near infrared (NIR) region due to the weak light absorption and relatively short carrier lifetime of the graphene. $\mathrm{TiO}_{2}$ [27] and $\mathrm{Al}_{2} \mathrm{O}_{3}$ anti-reflection layers [28] have been employed to enhance the photoresponse in the UV region. Recently, graphene/Si Schottky structure with an $\mathrm{Al}_{2} \mathrm{O}_{3}$ antireflective layer has been fabricated for UV photodetection, resulting in $0.2 \mathrm{~A} / \mathrm{W} R, 5 \mathrm{~ns}$ response time, $1.6 \times 10^{13} \mathrm{~cm} \cdot \mathrm{Hz}^{1 / 2} / \mathrm{W} D^{*}$ in wavelength range from 200 to $400 \mathrm{~nm}$, comparable to those of state-of-the-art $\mathrm{Si}, \mathrm{GaN}$, and $\mathrm{SiC}$ Schottky PDs.

Unlike traditional transparent electrodes, such as indium tin oxide or ultrathin metals, unique absorption properties of graphene in the UV range contribute to increasing the lifetime of hot electrons, thereby leading to large PC. Recently, a variety of graphene/Si-based structures have been proposed to improve the device performance. A new approach of integrating graphene/Si PD with two-dimensional (2D) Pt nanoparticles (NPs) has proven to enhance the $R$ and response time of the PD at the same time, as shown in Figure 1d [29]. Furthermore, the work function of graphene is increased by the physical doping with Pt NPs, thereby heightening the barrier of the Schottky junction, resulting in faster response and higher sensitivity, as shown in Figure 1e,f. Molybdenum 
oxide $\left(\mathrm{MoO}_{3}\right)$ has been widely used for improving the performance of the PD in organic electronics due to its high work function $[104,105]$ and dramatic surface-transfer hole-doping effect for a variety of $2 \mathrm{D}$ materials such as graphene and $\mathrm{MoS}_{2}$. The functionalization of the $\mathrm{MoO}_{3}$ layer on graphene led to a significant performance enhancement of the graphene/Si PDs [30], based on the surface-transfer doping effect, thereby reducing the series resistance of the graphene/Si Schottky barrier, resulting in $5.4 \times 10^{12} \mathrm{~cm} \cdot \mathrm{Hz}^{1 / 2} / \mathrm{W} D^{*}$. However, the interface between graphene and Si normally contains relatively-high density of surface states, resulting in large leakage current, which can limit the overall $D^{*}$ of the graphene/Si PD [24,25]. Recently, the DC of the graphene/Si junction was reduced by two orders at 0 bias by employing a thin interface thin oxide layer [31]. The graphene/thin $\mathrm{SiO}_{2} / \mathrm{Si} \mathrm{PD}$ showed $0.0078 \mathrm{pW} \cdot \mathrm{Hz}^{-1 / 2} \mathrm{NEP}$ at room temperature, resulting in $D^{*}$ up to $4.08 \times 10^{13} \mathrm{~cm} \cdot \mathrm{Hz}^{1 / 2} / \mathrm{W}$.

In addition, graphene $/ \mathrm{Si}$ Schottky diodes were fabricated in parallel with graphene $/ \mathrm{SiO}_{2} / \mathrm{Si}$ capacitors for high-performance optical detection [32], thereby showing $R / D^{*}$ of $3 \mathrm{~A} \cdot \mathrm{W}^{-1} / 3.5 \times 10^{12} \mathrm{~cm} \cdot \mathrm{Hz}^{1 / 2} \cdot \mathrm{W}^{-1}$ in the visible range. Here, the PC exceeded the forward current because the photogenerated minority carriers accumulated in the $\mathrm{Si} / \mathrm{SiO}_{2}$ interface diffused to the graphene/Si junction. According to another approach, the PC in graphene-based hybrid photodiodes was not only very efficiently generated in the graphene/Si Schottky barrier region but also in the adjacent graphene $/ \mathrm{SiO}_{2} / \mathrm{Si}$ region due to the reverse bias voltage [33]. The PC in the graphene $/ \mathrm{SiO}_{2} / \mathrm{Si}$ region rose sharply by about one order of magnitude at voltages exceeding a certain threshold bias, regardless of the incident laser power. In $\mathrm{Si}$ under $\mathrm{SiO}_{2}$, the inversion layer not only provided a low resistance path for minority charge transport, but also acted as a passivation layer on the surface states of $\mathrm{SiO}_{2}$ to effectively collect the charge carriers, resulting in improved PC. These results provide guidelines for establishing the fundamental mechanism of PC generation in graphene-based hybrid optoelectronic devices and for designing hybrid photodetectors based on combinations of two- and three-dimensional materials. The PD was also fabricated by directly growing graphene nanowalls on a Si substrate instead of using graphene layers CVD-grown via a metal catalyst [27]. Resulting $D^{*}$ was $5.88 \times 10^{13} \mathrm{~cm} \cdot \mathrm{Hz}^{1 / 2} / \mathrm{W}$, higher than ever reported in the planar graphene/Si based PDs, thanks to the ultra-low current noise of $3.18 \mathrm{fA} \cdot \mathrm{Hz}^{1 / 2}$, which can be attributed to the excellent junction quality of $0.69 \mathrm{eV}$ barrier height and 1.18 ideal factor. Other principal PD parameters were $10^{7} \mathrm{PC} / \mathrm{DC}\left(I_{\text {light }} / I_{\text {dark }}\right)$ ratio, $40 \mu$ s response time, $8.5 \mathrm{kHz}$ cutoff frequency, and $0.52 \mathrm{~A} / \mathrm{W} R$.

\subsection{Graphene/One- and Two-Dimensional Silicon}

Two-dimensional Si nanostructures such as porous Si (PSi) and Si NWs have high ratio of surface to volume/light absorption, very useful for their application in graphene-based PDs. Figure 2a shows a schematic diagram of a graphene/PSi Schottky diode. Graphene/PSi Schottky diodes have been successfully fabricated to show excellent PD performance including $60 \%$ EQE and $3 \mu$ s response time, relatively higher than the graphene/Si wafer PDs in the near-UV wavelength range, as shown in Figure 2c [35]. The performance of the graphene/PSi PDs can be further improved by optimizing the device structure and the pore depth of PSi. Alternatively, the NIR PDs fabricated based on a structure of graphene/Si NW array decorated with Au NPs [36] showed high performance of $10^{6} I_{\text {light }} / I_{\text {dark }}$ ratio and high response speed (rise/fall time of $73 / 96 \mu \mathrm{s}$ ), better than those of pure graphene/Si NWs heterojunction [106], as shown in Figure 2c,d. These high PD parameters possibly resulted from the enhanced optical absorption due to the strong optical trapping effect of Si NW arrays and the surface plasmon coupling by Au NPs. 

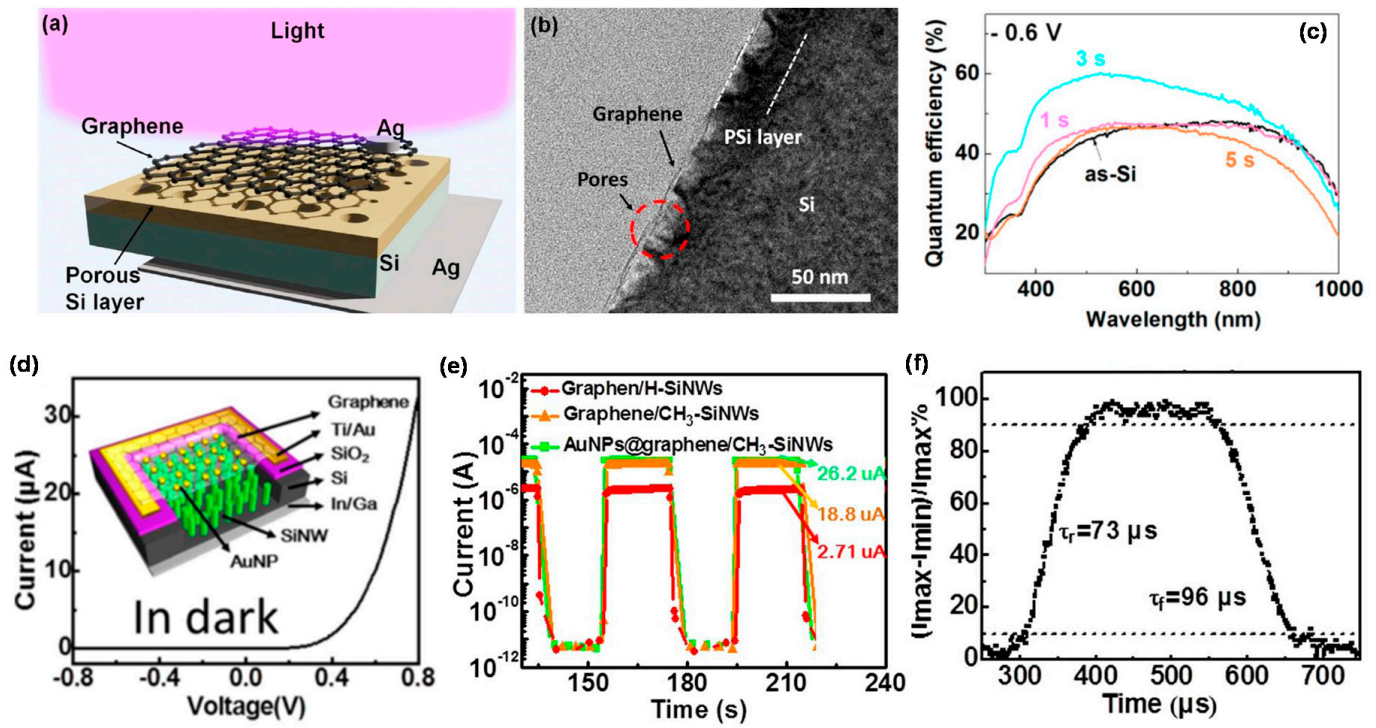

Figure 2. (a) Schematic diagram of graphene/PSi/n-Si PD with silver top and bottom electrodes under light illumination; (b) Cross-sectional transmission electron microscopy (TEM) image of graphene/PSi junction; (c) Quantum efficiencies of as-Si, 1, 3, and 5 s PDs (Here, 1, 3, and 5 s mean the deposition time $\left(t_{d}\right)$ of Ag nanoparticles. That is, the pore on the surface of the PSi increases as the time increases, Reproduced with permission for Figure 2a-c from 2014 ACS Applied Materials \& Interfaces [35]; (d) Current-voltage curves of the Au NPs-graphene/SiNWs array PD. The inset shows the device structure; (e) Photoresponse of three representative devices under $850 \mathrm{~nm}$ light illumination at $V=0$; (f) A single normalized cycle measured at $2200 \mathrm{~Hz}$ for estimating both rise time $\left(t_{r}\right)$ and fall time $\left(t_{f}\right)$. Reproduced with permission for Figure 2d-f from 2014 Scientific Reports [36].

\subsection{Graphene/Zero-Dimensional Silicon}

$\mathrm{Si}$ is widely used as a broadband PD, but is limited in its use for wider applications due to the inherent indirect bandgap nature. Especially, graphene/Si-based PD exhibits fast photoresponse in the UV and NIR regions, but not in the visible region. One way to overcome this drawback is to form $\mathrm{Si}$ quantum dots (SQDs) [107,108]. SQDs within a $\mathrm{SiO}_{2}$ matrix allow for large light absorption in the visible range based on the quantum confinement effect [37,38]. Recently, $\mathrm{AuCl}_{3}$-doped graphene/SQDs: $\mathrm{SiO}_{2}$ multilayers (MLs)/Si PDs were successfully fabricated to show $0.35 \mathrm{~A} / \mathrm{W} R$ and $10^{9} \mathrm{~cm} \cdot \mathrm{Hz}^{1 / 2} / \mathrm{W} D^{*}$ near the wavelength of $600 \mathrm{~nm}$, indicating considerable performance improvement in the visible region due to the strong photoresponse of SQDs [37,38]. The novel DC/PC behaviors are dominated by the tunneling of the charge carriers, depending on the SQD size and $\mathrm{AuCl}_{3}$ doping concentration $\left(n_{D}\right)$. However, the performance of the PD is limited by the surface of the $\mathrm{AuCl}_{3}$-doped graphene on which light is first irradiated due to large reduction in transmittance by the Au NPs formed by the doping. Recently, long-term stabilities have been remarkably enhanced by employing bis(trifluoromethanesulfonyl)-amide (TFSA) with low resistance and high transparency as a dopant for graphene, as shown in Figure 3a [39]. Figure 3b,c shows spectral $R$ and $D^{*}$ of the TFSA-doped graphene/SQD: $\mathrm{SiO}_{2} \mathrm{MLs} / \mathrm{Si} \mathrm{PDs}$ with $0.413 \mathrm{~A} / \mathrm{W}$ and $10^{10} \mathrm{~Hz}^{1 / 2} / \mathrm{W}$ at the peak wavelength of $630 \mathrm{~nm}$ under low voltage $(-2 \mathrm{~V})$, respectively, significantly better than the $\mathrm{AuCl}_{3}$-doped graphene PDs, indicating minimization of the optical loss by the use of TFSA. On the other hand, graphene/Si Schottky junction PDs with SQDs on top of the graphene, as show in Figure 3d [40], showed excellent performances of $6.7 \mathrm{pW} \cdot \mathrm{Hz}^{-1 / 2} \mathrm{NEP}, 7.4 \times 10^{9} \mathrm{~cm} \cdot \mathrm{Hz}^{1 / 2} / \mathrm{W} \mathrm{D}^{*}$, and response time $\leq 25 \mathrm{~ns}$, possibly resulting from significant reduction of the optical reflections, contributed by the SQDs, as shown in Figure 3e,f. In another approach, high-sensitivity NIR detection of SQDs/graphene/Si hybrid phototransistors was demonstrated based on the plasmonic effect of SQDs doped with boron [41]. 
The local surface plasmon resonance of B-doped SQDs improves the NIR absorption of graphene, resulting in excellent light output characteristics in the UV to NIR region.

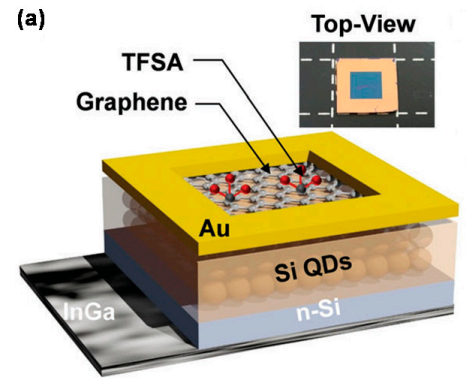

(d)

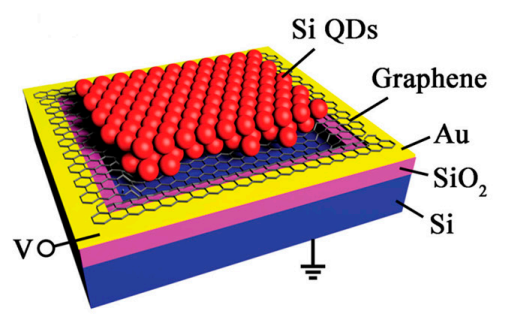



(e)

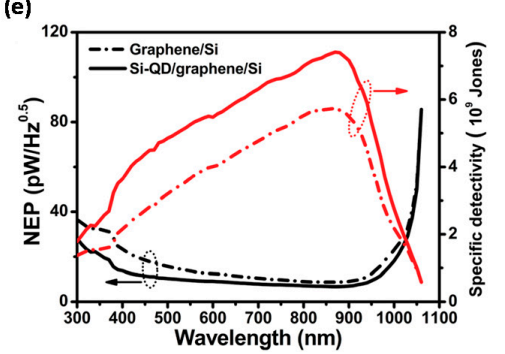

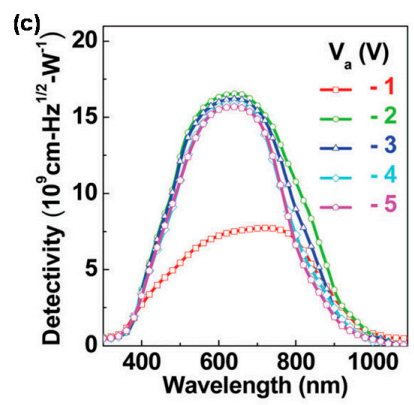

(f) Graphene/Si Si-QD/graphene/Si

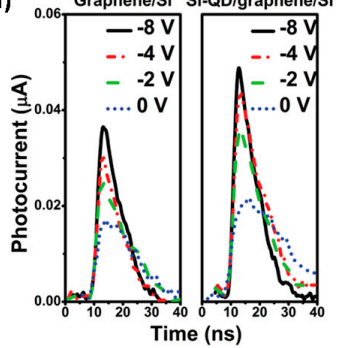

Figure 3. (a) Schematic of a typical TFSA-doped graphene/SQDs: $\mathrm{SiO}_{2} \mathrm{MLs} / \mathrm{n}$-type Si wafer PD with $\mathrm{Au}$ and InGa as the top and bottom electrodes, respectively; (b) Spectral responsivity and quantum efficiency at a bias of $-2 \mathrm{~V}$; (c) Spectral detectivity under various bias voltages. Here, the doping concentration is $20 \mathrm{mM}$. Reproduced with permission for Figure $3 \mathrm{a}-\mathrm{c}$ from 2017 Journal of Materials Chemistry C [39]; (d) Schematic diagram of a typical Si-QDs/graphene/Si PD; (e) Spectral dependence of the NEP and corresponding specific detectivity of the graphene/Si and Si-QDs/graphene/Si PDs. The minimum NEP and the maximum $D^{*}$ of the Si-QDs/graphene/Si PD are $6.7 \mathrm{pW} \cdot \mathrm{Hz}^{-1 / 2}$ and $7.4 \times 10^{9}$ Jones, respectively, at $\lambda \approx 877 \mathrm{~nm}$; (f) Time-dependent PC of both the graphene/Si and $\mathrm{Si}-\mathrm{QDs}$ /graphene/Si PDs under the bias voltages of $0,-2,-4$, and $-8 \mathrm{~V}$. Reproduced with permission for Figure 3d-f from 2016 Advanced Materials [40].

\section{Graphene/III-V Semiconductors}

\subsection{Graphene/GaN}

GaN is a wide direct bandgap semiconductor with excellent optical/electrical properties and high chemical stabilities at high temperature, and has been employed in various PD applications. Graphene/GaN heterostructures are useful for light detection in the UV/visible region based on Schottky diode junction [42,43]. Graphene-TCE based GaN Schottky diode for UV detectors [42] has shown excellent performance of high $I_{\text {light }} / I_{\text {dark }}$ ratio $\left(10^{5}\right)$ under UV illumination. In another approach, UV PDs were successfully fabricated by transferring large-area graphene TCE on vertically-standing GaN NW array as a light absorbing media, as shown in Figure 4a [43]. Figure 4b shows extremely-high $R$ of $25 \mathrm{~A} / \mathrm{W}$ at $357 \mathrm{~nm}$. These results represent a potential application of the graphene/GaN junctions in various optoelectronic devices operating in the UV region. 



Figure 4. (a) Scanning electron microscopy (SEM) image of a graphene film on GaN NWs; (b) Responsivity for various incident power densities. The inset shows the photocurrent spectrum of the PD. Reproduced with permission for Figure 4a,b from 2013 Applied Physics Letters [43]; (c) Schematic illustration of the graphene/GaAs nanocone array device; (d) A typical cross-sectional SEM image of the $n$-GaAs nanocones array after etching; (e) Single normalized cycle at $50 \mathrm{~Hz}$ to find both rise time $\left(\tau_{r}\right)$ and fall time $\left(\tau_{f}\right)$. Reproduced with permission for Figure 4c-e from 2014 Advanced Functional Materials [44].

\subsection{Graphene/GaAs}

GaAs has long been considered as an ideal candidate material for NIR PD applications due to its striking electrical/optical properties such as high carrier mobility, direct bandgap of $\sim 1.4 \mathrm{eV}$, and large optical absorption coefficient. As shown in Figure $4 \mathrm{c}, \mathrm{d}$, graphene TCE was applied for GaAs nanocone array-based NIR light detection [44], resulting in reproducible PD performance of $10^{4} I_{\text {light }} / I_{\text {dark }}$ ratio, $1.73 \mathrm{~mA} / \mathrm{W} \mathrm{R}$, and $10^{11} \mathrm{~cm} \cdot \mathrm{Hz}^{1 / 2} / \mathrm{W}$ under $850 \mathrm{~nm}$ illumination. The $\mathrm{PD}$ also showed fast response speed with rise/fall times of $72 / 122 \mu$ s, as shown in Figure 4e. These results are believed to originate from the GaAs nanocone arrays, which can efficiently trap incident NIR light, consistent with previous report [45]. Recently, $\mathrm{AlO}_{x}$ thin layer was employed for optimizing $R$ of the graphene/GaAs NIR PD. Here, the $\mathrm{AlO}_{\mathrm{x}}$ serves not only as a surface protective layer for suppressing the carrier recombination, but also as a barrier for reducing the current leakage [46], thereby leading to significant increase/decrease in $\mathrm{PC} / \mathrm{DC}$, respectively. With the use of the $\mathrm{AlO}_{\mathrm{x}}$ layer, the $R$ and specific $D^{*}$ increased by 4 times to $5 \mathrm{~mA} / \mathrm{W}$ and $2.8 \times 10^{11} \mathrm{~cm} \cdot \mathrm{Hz}^{1 / 2} / \mathrm{W}$, respectively, whilst rise/fall times sharply decreased to $320 / 380 \mathrm{~ns}$.

\section{Graphene/Metal Oxides}

\subsection{Graphene/ZnO}

$\mathrm{ZnO}$ has received considerable attention over the past two decades due to its unique properties such as direct bandgap of $3.2 \mathrm{eV}$, large exciton binding energy of $\sim 60 \mathrm{meV}$, high transmittance $(>80 \%)$ in the wavelength range of $400-800 \mathrm{~nm}$, and wide-variable conductivity in the metallic to insulating range $[109,110]$. To date, graphene/ZnO heterostructures have been extensively studied for PD application. Recently, a seedless solution process has been developed for controllable growth of crystalline $\mathrm{ZnO}$ micro-/nano-wire arrays on graphene for UV PDs [47-52], showing high response of $1.62 \mathrm{~A} / \mathrm{W}$, better than the sensors made of epitaxial-ZnO [111] or ZnO-nanoparticles [112]. In another approach, novel $\mathrm{ZnO}$-QDs-based heterostructures were combined with graphene layers for PDs to 
show excellent visible-blind UV photoresponse [48], resulting from the reduction of the DC, caused by the formation of the potential barriers between adjacent $\mathrm{ZnO}$ QDs and between graphene and $\mathrm{ZnO}$ QDs. It has also been reported that phototransistors composed of $\mathrm{ZnO}$ nanostructure as light harvesting medium and graphene as conducting channel [49-56]. Figure 5a,b shows the effective charge transfer between ZnO QDs and graphene [49]. Under UV irradiation, the holes separated from the electrons under photoexcitation are captured by the surface states to discharge the absorbed oxygen ions on the surface of the ZnO QDs. The unpaired electrons with a relatively long lifetime move to the graphene layer and then transport in the graphene channel, leading to modulation of the transport characteristics of graphene. When UV light is turned off, the surrounding oxygen molecules are re-adsorbed on the QD surface, thereby trapping electrons and lowering the Fermi energy level, resulting in the recovery of the transport characteristics of the graphene. This photogeneration effect could lead to high photoconductive gain of $10^{7}$ through further device optimization, as shown in Figure 5c.
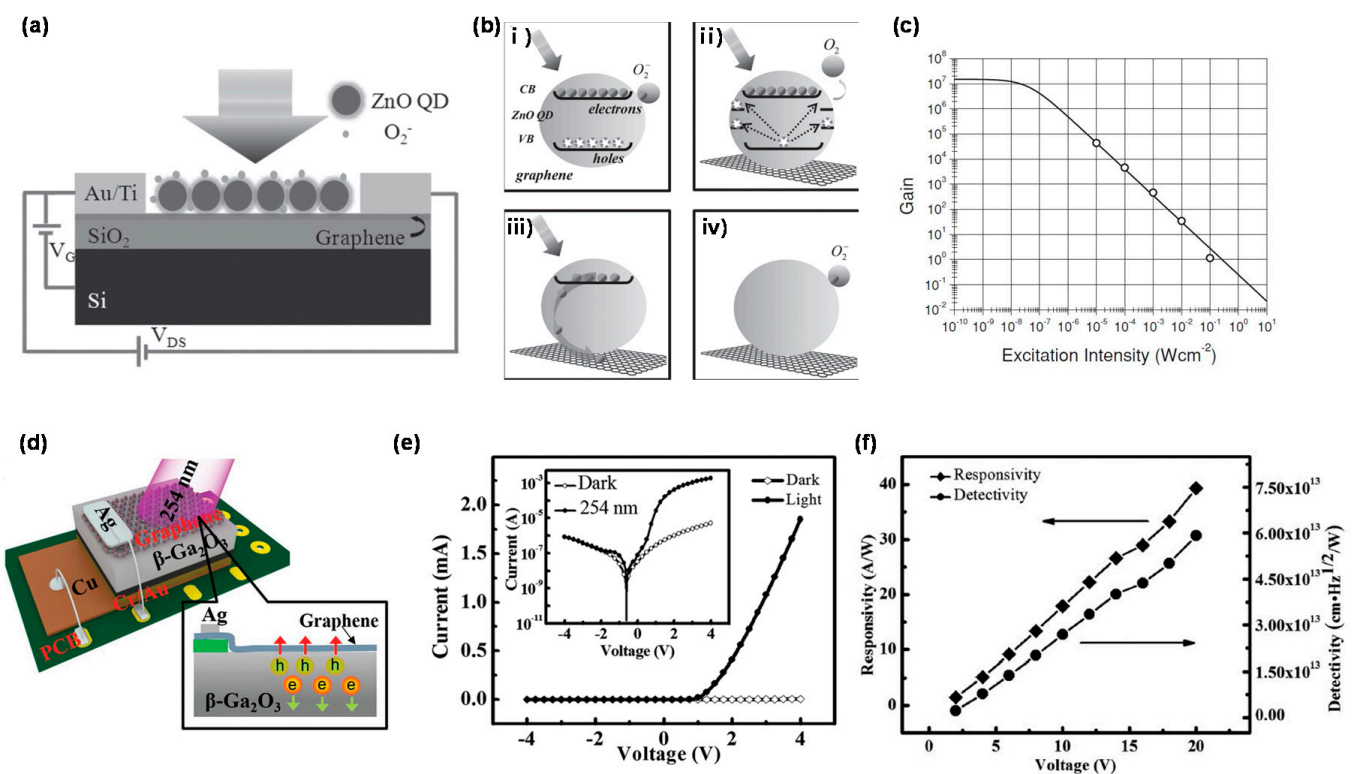

Figure 5. (a) Schematics of the graphene device coated with ZnO QDs; (b) The mechanism of the oxygen-assisted charge transfer process. (i) With irradiation of photon energy larger than the bandgap of the QDs, electron-hole pairs are generated; (ii) The holes are trapped at the surface states, leaving behind the unpaired electrons. The trapped holes will discharge the oxygen ions on the surface, and the oxygen molecules are desorbed; (iii) The electrons will transfer from the QDs to the graphene layer; (iv) With laser turned off, no more electron-hole pairs are generated. The oxygen molecules will re-adsorb on QDs and capture the remaining electrons to form oxygen ions on the surface; (c) Gain as a function of excitation intensity. Reproduced with permission for Figure 5a-c from 2013 Small [49]; (d) Schematic diagram of the MLG/ $\beta-\mathrm{Ga}_{2} \mathrm{O}_{3} \mathrm{PD}$; (e) Current-voltage characteristics of the device under dark and $254 \mathrm{~nm}$-light irradiation. The inset shows the current-voltage curves on a logarithmic scale (f) Responsivity and detectivity of the multi-layer graphene- $\mathrm{Ga}_{2} \mathrm{O}_{3}$ heterojunction $\mathrm{PD}$ as a function of different bias voltages. Reproduced with permission for Figure 5d-f from 2016 Advanced Materials [69].

In recent years, $\mathrm{ZnO} \mathrm{NW}$ or nanorod (NR) arrays have been combined with various graphene sheets on rigid or flexible substrates to form UV phototransistors [50-54]. ZnO NR array was grown on the channel of the graphene field-effect transistor (FET) by the hydrothermal method to successfully fabricate the UV PDs [50], showing high sensitivity/wavelength selectivity, but still quite a slow response/recovery under UV illumination at low power. In other studies, UV phototransistors were fabricated with organic self-assembled monolayer (SAM), sandwiched between inorganic $\mathrm{ZnO}-\mathrm{QDs}$-decorated graphene channel and conventional $\mathrm{SiO}_{2} / \mathrm{Si}$ substrate [55]. Surprisingly, 
the mobility of the chemically-deposited graphene channel is higher on the $\mathrm{SAM}$ than on the $\mathrm{SiO}_{2}$, thereby greatly reducing the time of the electron transfer in the channel. As a result, the photogenerated electrons transferred from the QD to the graphene are recycled several times before recombination, resulting in the increase of the photoconductivity gain. The phototransistors exhibited $\sim 10^{8} \mathrm{~A} / \mathrm{W} R$ corresponding to $\sim 3 \times 10^{9}$ gain, $\sim 10^{3} \mathrm{UV} /$ visible rejection ratio, and $\sim 5.1 \times 10^{13} \mathrm{~cm} \cdot \mathrm{Hz}^{1 / 2} / \mathrm{W}$ specific $D^{*}$. More recently, phototransistors consisting of graphene FET and ZnO QDs have been fabricated based on surface active process [56]. Resulting $D^{*}$ increased up to $7.5 \times 10^{14}$ Jones due to the efficient transfer of charge carriers from $\mathrm{ZnO}$ QDs to graphene. These results suggest how important the van der Waals interface is for the efficient optoelectronic processes in heterostructure PDs. On the other hand, in graphene/ $\mathrm{ZnO}$ heterostructures photodiodes [57-67], the photogenerated electron/hole pairs were found to be separated by the built-in potential even at zero bias, thereby potentially reducing the DC, resulting in the increase of specific $D^{*}[61,64,66]$. The response of the photodiode was shown to be much faster than that of the phototransistor-type PD by further increasing the built-in electric field under moderate reverse bias $[57,59,60,62,63]$. In addition, large internal current gain could also be obtained due to the impact ionization of the photocarriers with sufficient energy [16].

A Schottky-junction-type UV PD fabricated by depositing graphene layer on ZnO NR array was shown to be highly sensitive to UV illumination with excellent operational stability and reproducibility, resulting in $113 \mathrm{~A} / \mathrm{W} R$ and 385 gains at $-1 \mathrm{~V}$ [57]. The response speed was remarkably fast (rise/fall time: $0.7 / 3.6 \mathrm{~ms}$ ) due to the strong light trapping effect by high-crystallinity $\mathrm{ZnO} \mathrm{NR}$ array. The PD could also monitor the pulse light at high frequencies of $2250 \mathrm{~Hz}$. The PD performance was further improved by employing charge tunneling/blocking interlayer [58] and by modulating the Schottky barrier through back gating [59] or external deformation [60,62]. The $\mathrm{R}$ was also enhanced up to $1350 \mathrm{~A} / \mathrm{W}$ at $\sim 5 \mathrm{~V}$ by inserting a hexagonal boron nitride (h-BN) layer into the graphene/ZnO Schottky junction [58]. The h-BN interface layer reduced the DC by suppressing the electron transfer from graphene to $\mathrm{ZnO}$, and suppressed the recombination of carriers, resulting in the increase of the PC, by holding photogenerated electrons in $\mathrm{ZnO}$.

Recently, the effect of strain modulation on PD performance was studied for a flexible graphene/ZnO nanostructure $[60,65]$. The $R$, measured under an external strain of 5 to $30 \%$, showed maximum $17 \mu \mathrm{A} / \mathrm{W}$ and $3.8 \mu \mathrm{A} / \mathrm{W}$ at a strain of $30 \%$ for $\mathrm{UV}$ and visible light, respectively [65]. The compressive strain causes $\mathrm{ZnO}$ to generate a negative piezoelectric potential, and the charge begins to accumulate near the conduction band, lowering the conduction band energy. When the conduction band energy is lowered, the Schottky barrier is increased and the sensitivity of the graphene/ $\mathrm{ZnO}$ $\mathrm{PD}$ is improved due to an increase in the width of the depletion region, which is advantageous for the photogenerated electron-hole pair separation. The theoretical simulation results also showed that the piezo-potential was mainly distributed at the end of the $\mathrm{ZnO}$ nanostructure, advantageous for the effective modulation of the graphene/ZnO Schottky junction.

\subsection{Graphenene/Other Metal Oxides}

Like graphene/ $\mathrm{ZnO}$ hybrid structures, other semiconductor metal oxides including $\mathrm{ZrO}_{2}$ [68], $\mathrm{Ga}_{2} \mathrm{O}_{3}[69,70]$ have also been integrated with graphene to form heterostructures for PD applications. $\mathrm{ZrO}_{2}$ is a promising material for deep-UV detection applications. Recently, in the $\mathrm{ZrO}_{2}$ QDs-graphene heterostructure, $R$ was shown to be as high as $22 \mathrm{~A} / \mathrm{W}$ at a deep-UV wavelength of $254 \mathrm{~nm}$ [68]. In the $\mathrm{PD}$, the holes photo-excited in graphene can be circulated through the external circuit several times under bias voltage before recombining with the electrons photo-excited/collected in the $\mathrm{ZrO}_{2}$ layer due to the high mobility of graphene. This explains why $R$ is so extremely high

As another approach, a deep UV photodiode was fabricated based on multilayer graphene $/ \mathrm{Ga}_{2} \mathrm{O}_{3}$ junctions, as shown in Figure 5d [69], exhibiting a significant current increase at forward bias voltage during deep-UV illumination $(254 \mathrm{~nm})$, as shown in Figure $5 \mathrm{e}$. Figure $5 \mathrm{f}$ shows the $R$ and $D^{*}$ of $39.3 \mathrm{~A} / \mathrm{W}$ and $5.92 \times 10^{13}$ Jones, respectively, comparable to, or even better than, $\mathrm{Ga}_{2} \mathrm{O}_{3}$ nanostructure-based PDs. The PD parameters were reproducible and stable even by repeated 
measurements under UV illumination, showed maxima at $\sim 220 \mathrm{~nm}$, but were almost blinded to light at wavelengths longer than $280 \mathrm{~nm}$. Most recently, graphene $/ \mathrm{Ga}_{2} \mathrm{O}_{3} /$ graphene PD showed apparent rectifying characteristics and excellent solar-blind UV photoresponse [70] with fast rise/fall times of $0.96 / 0.81 \mathrm{~s}$ and $I_{\text {light }} / I_{\text {dark }}$ ratio up to 82.88 under $254 \mathrm{~nm}$ illumination.

\section{Graphene/Organic Semiconductors}

Organic semiconductors including small molecules and polymers are very attractive in practical view due to their simple solution production processes at low temperatures [113], low cost, and light weight [114,115]. Graphene/P3HT hybrid heterostructures showed an $R$ about 10 times larger on a piezoelectric substrate than on $\mathrm{SiO}_{2}$ substrate [71]. The improved light response was attributed to the vertical field of the polarization of the piezoelectric substrate, which facilitates the spatial separation of the photo-generated electrons and holes, thereby enhancing the hole doping of graphene.

Figure $6 \mathrm{a}, \mathrm{b}$ shows a typical graphene/pentacene heterostructure that serves as a multifunctional PD with nonvolatile memory (NVM) function for storing optical signals [72]. The PD exhibited excellent photoresponse at 400-800 nm with maximum $R$ and specific $D^{*}$ being $700 \mathrm{~A} / \mathrm{W}$ and of $10^{13}$ Jones, respectively, as shown in Figure 6c. Large hysteresis was observed in the transfer characteristics, in which the Dirac point voltage was shifted toward the positive gate voltage under dark and illumination. This hysteresis behavior was understood by the trapping/detrapping of the charge carriers in the Au NPs, resulting from the tunneling through the dielectric layer. The PD also showed excellent retention characteristics with retention times exceeding $10^{4} \mathrm{~s}$ and PC being invariant for more than 200 cycles (Figure 6e,f). It was also found that as the optical power increased, the PC increased stepwise, indicating multiple NVM.


(d)


Figure 6. (a) Schematic diagram of the device structure comprising a graphene PD with a pentacene light absorption layer and an Au NP charge trapping layer. In the device, the ITO acts as a gate electrode and $\mathrm{Au}$ as source/drain electrode; (b) Photographic image of the graphene PD fabricated on a PEN substrate; (c) Photoresponsivity and photodetectivity vs. illumination power; (d) Two-dimensional spatial profile of $\left|E^{2}\right|$ of the hybrid PD with or without Au NPs; (e) Retention time and (f) cycling tests of the graphene PD with a memory functionality under various illumination powers. Reproduced with permission for Figure 6a-f from 2015 Nano Letters [72]. 
For a phototransistor-type PD structure, monolayer organic C8-BTBT crystals were prepared on graphene by van der Waals epitaxy [73], and was shown to exhibit the $R$ larger than $10^{4} \mathrm{~A} / \mathrm{W}$. By employing multilayer C8-BTBT, the $R$ was further enhanced to $4.76 \times 10^{5} \mathrm{~A} / \mathrm{W}$. This outstanding photoresponse was attributed to the ultrahigh photoconductive gain and the efficient interfacial charge transfer efficiency due to the high quality of C8-BTBT layer and graphene/C8-BTBT interface. The response speed was $\sim 25 \mathrm{~ms}$ for the monolayer PD, but increased to $\sim 830 \mathrm{~ms}$ for the multilayer PD, dominated by interlayer hopping of trapped carriers within C8-BTBT crystals.

\section{Graphene/Perovskites}

Perovskites have recently received strong attention as next-generation PD materials because of their high adsorption coefficient, tunable bandgap, small exciton binding energy, long carrier diffusion length, ambipolar charge transport, and high carrier mobility [116-121]. The perovskite material has a specific crystal structure as $\mathrm{ABX}_{3}$ formula. The larger $A$ cations occupy cuboctahedral sites shared with twelve $X$ anions, while smaller $B$ cations stabilize at octahedral sites shared with six $X$ anions. Organic-inorganic halide perovskite materials are commonly used in solar energy applications. The graphene/perovskite hybrid structure is very useful for taking advantage of the synergy effect based on the unique properties of graphene and perovskite materials. Figure 7 shows a typical early-stage phototransistor composed of graphene $/ \mathrm{CH}_{3} \mathrm{NH}_{3} \mathrm{PbI}_{3}\left(\mathrm{MAPbI}_{3}\right)$ hybrid, exhibiting the $R$ of several hundreds of $\mathrm{A} / \mathrm{W}$ and relatively-rapid response time shorter than $1 \mathrm{~s}$ in the UV-visible range $[74,75]$. Especially, Figure $7 \mathrm{~d}$ shows on-off switching behaviors of the perovskite-graphene PD with rise and fall times of 87 and $540 \mathrm{~ms}$, respectively. These results show the robustness and reproducibility of the device.

(a)

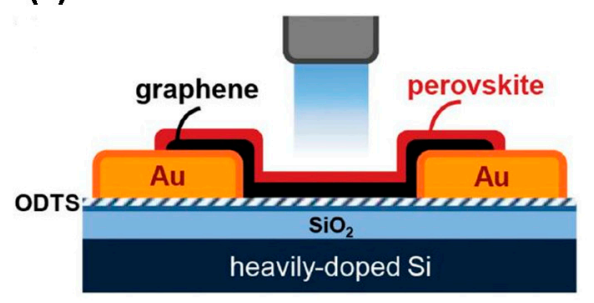

(b)

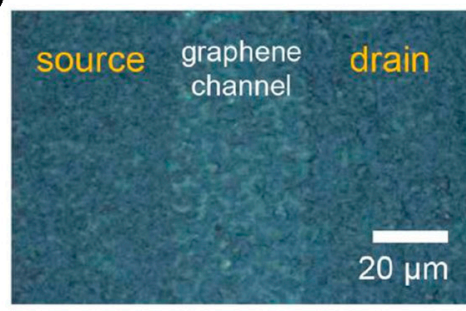

(c)

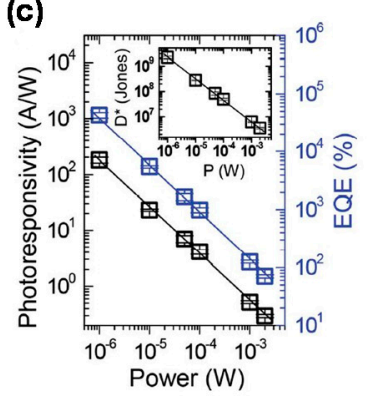

(d)

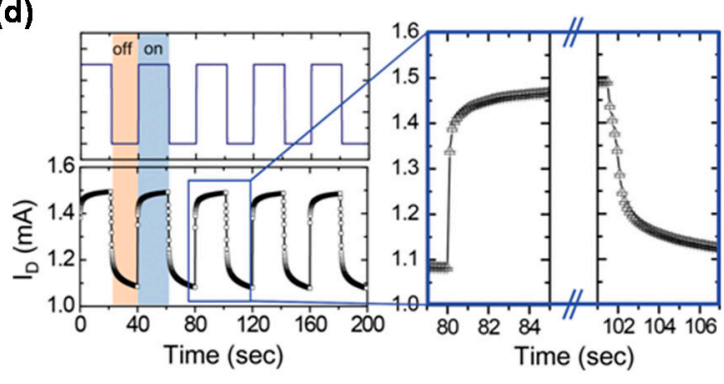

Figure 7. (a) Schematic diagram of the perovskite-graphene hybrid PD; (b) Optical microscopy image of the $\mathrm{CH}_{3} \mathrm{NH}_{3} \mathrm{PbI}_{3}$-graphene PD; (c) Photoresponsivity and EQE vs. illumination power. The inset shows the photodetectivity $\left(D^{*}\right)$ vs. illumination power; (d) On-off switching characteristics of the PD under dark and light illumination. By the pulsed laser illumination (left top), the temporal response of the photocurrent is shown (left bottom). Reproduced with permission for Figure 7a-d from 2014 Advanced Materials [74].

It is currently difficult to compare the performances of the graphene/ $\mathrm{MAPbI}$ hybrid phototransistors with those of graphene-based other semiconductor hybrid PDs operated based on similar mechanisms [21,22,122], but they are several times higher than those of pure graphene-based PDs [123]. The enhanced photoresponse performance can be attributed to the transfer of electrons 
from the graphene to the proximate perovskite layer to fill the empty states in the valence band of the perovskite layer, resulting in the reduction of the recombination of the photocarriers. The electron trapping process was demonstrated by the dramatic quenching of the PL intensity in the graphene/perovskite system. In another approach, the graphene/MAPbI 3 stack was integrated with $\mathrm{Au}$ NPs having a plasmon resonance peak at $\sim 530 \mathrm{~nm}$, as shown in Figure 8 , to fabricate the hybrid phototransistors showing higher $R$ and faster response speed [76]. The higher $R$ was attributed to the light-harvesting effect enhanced by the near-field of the perovskite, induced by the plasmonic coupling of $\mathrm{Au}$ NPs. Furthermore, the time for these carriers to diffuse into graphene is shorter than that for carriers generated far from the perovskite-graphene interface, thus leading to the faster operation in the PD by the plasmonic effect.

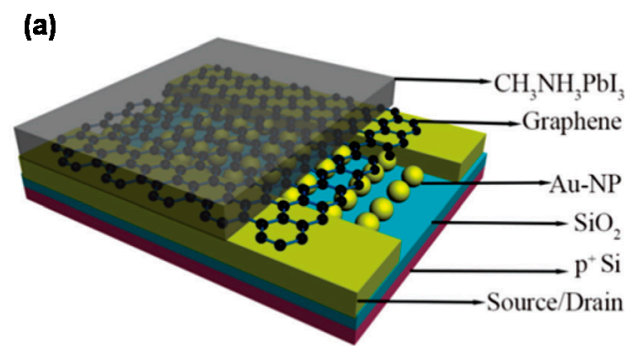

(c)

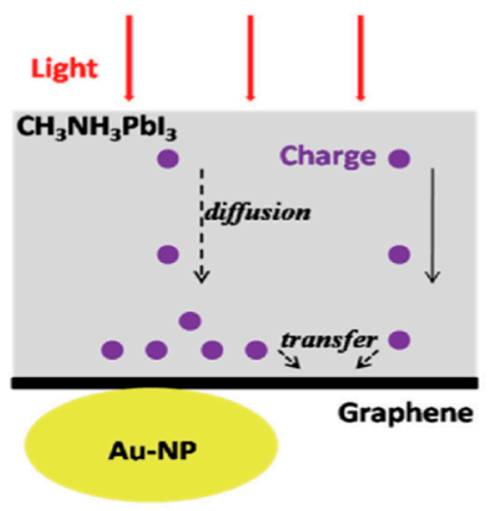

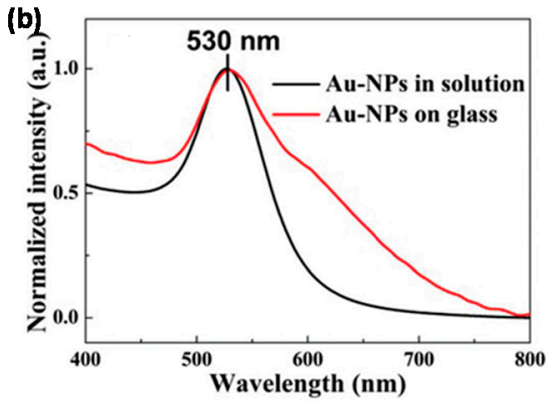

(d)



Figure 8. (a) Schematic of the $\mathrm{CH}_{3} \mathrm{NH}_{3} \mathrm{PbI}_{3}$-graphene- $\mathrm{Au} \mathrm{NP}$ hybrid system device architecture (b) UV-Vis absorbance spectrum of Au-NPs on a 3-aminopropyltriethoxysilane-coated glass; (c) Schematic of generation, diffusion, and transfer of photo-induced carriers in the perovskite layer with and without the influence of gold NPs; (d) Response time study on a single representative light/dark cycle. Reproduced with permission for Figure 8a-d from 2016 Nanoscale [76].

As an advanced step, the sequential vapor deposition method has been developed to grow ultra-flat $\mathrm{MAPbI}_{3}$ films on graphene, thereby forming a compact heterostructure for efficient light harvesting and exciton separation, as shown in Figure 9 [77]. This PD showed $1.73 \times 10^{7} \mathrm{~A} / \mathrm{W} R$ and $2 \times 10^{15}$ Jones $D^{*}$, several times larger than those of PD containing a $\mathrm{MAPbI}_{3}$ film prepared by conventional spin-coating method. Very recently, a thin layer of P3HT has been inserted between $\mathrm{MAPbI}_{3-\mathrm{x}} \mathrm{Cl}_{\mathrm{x}}$ perovskite and graphene as a hole transport layer for high-performance phototransistors [78]. In this study, the carrier diffusion length of the $\mathrm{MAPbI}_{3-\mathrm{x}} \mathrm{Cl}_{\mathrm{x}}$ perovskite was shown to be larger than that of the $\mathrm{MAPbI}_{3}$ perovskite, resulting in more efficient transfer of the photo-generated holes to the graphene side. In addition, the separation of the photo-generated electrons and holes was more effective due to the presence of the P3HT layer, thereby reducing the recombination of the optical carriers, resulting in the transport of high-density electrons to the perovskite layer. The gain of this PD was close to $10^{10}$, at least one order of magnitude higher than those of other PDs without the P3HT layer [21,22,122]. 
(a)



(c)

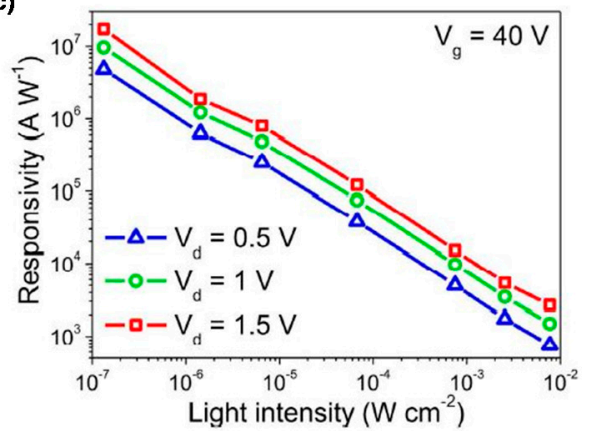

(b)

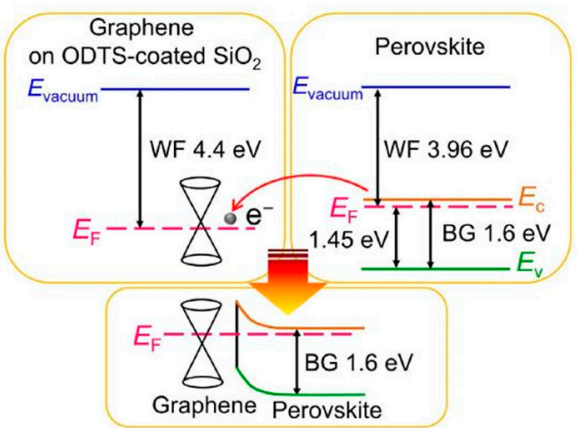

(d)

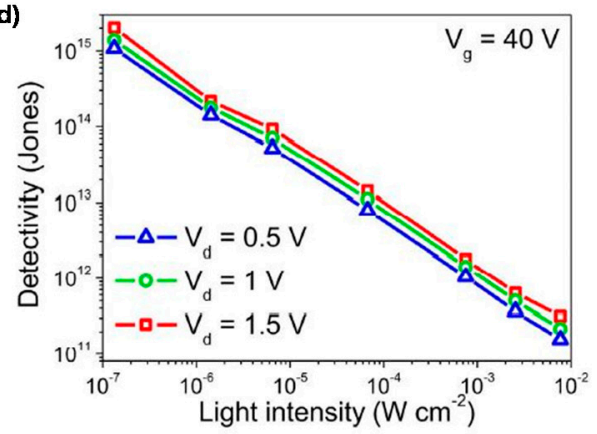

Figure 9. (a) Schematic illustration of the graphene-perovskite hybrid phototransistor. The inset shows the top-view optical microscopy image of the device; (b) Band diagrams of graphene and perovskite obtained from ultraviolet photoelectron spectroscopy spectra. The schematic diagram of the band bending at graphene/perovskite interfaces is illustrated below; (c) Responsivity and (d) detectivity of the hybrid phototransistor as functions of light intensity at three selected drain voltages. Reproduced with permission for Figure 9a-d from 2017 Scientific Reports [77].

Highly-crystalline perovskite nanostructures are advantageous for the photo-detection application because the recombination rate of the photo-generated carriers is much smaller in the bulk than in the thin film. Recently, the graphene/ $\mathrm{MAPbI}_{3} \mathrm{NWs}$ hybrid phototransistor was fabricated to show an $R$ as large as $10^{6} \mathrm{~A} / \mathrm{W}$ [79]. As another approach, the hybridization of graphene with $\mathrm{CsPbBr}_{3-\mathrm{x}} \mathrm{I}_{\mathrm{x}}$ nanocrystals (NCs) was done to fabricate phototransistors showing high $R$ [80]. This PD also exhibited ultrahigh specific $D^{*}\left(2.4 \times 10^{16}\right.$ Jones $)$ thanks to the extremely-high carrier mobility of the graphene, very promising for the application of the perovskite NCs in next-generation high-performance optoelectronics.

\section{Graphene/Carbon Nanomaterials}

Low-dimensional carbon materials such as fullerenes, carbon QDs, carbon nanotubes (CNTs), and graphene have attracted much interest over the past several decades due to their unique structural and physical properties [124-126]. Recently, various types of carbon nanomaterials have been integrated into hybrid structures including graphene/carbon nanomaterials, showing physical properties much better than those of the individual components [124,126].

\subsection{Graphene/Zero-Dimensional Carbon}

Zero-dimensional carbon materials including graphite QDs, graphene QDs, and C60 were deposited on the graphene by spin coating or thermal evaporation methods to form hybrid structures for high-performance phototransistor applications [81-85]. In this structure, for example, graphite QDs act as light-harvesting material whilst the graphene layer is a conducting pathway for high-speed carriers, and carbon conductive paste was used as an electrode to complete the PD, as shown in 
Figure 10a [81]. While light is irradiated, the holes move to the graphene, shown in Figure $10 \mathrm{~b}$. In contrast, the electrons in the QDs act as an effective local gate to modulate the conductance of the graphene through capacitive coupling. The $300 \mathrm{~nm} \mathrm{SiO} 2$ on $\mathrm{Si}$ was employed to investigate the properties of the intrinsic charge transfer between graphene and graphite QDs in the graphene FET, as shown in Figure 10a. Figure 10c shows the $I_{D S}-V_{g}$ characteristics of the graphene FET before and after the deposition of the graphite QDs. The Dirac points are $1.6 \mathrm{~V}$ and $48 \mathrm{~V}$ before and after doping the graphite QDs, respectively. In other words, a higher $V_{g}$ is required to access the Dirac point of the graphite QDs/graphene FET because the net negative charge of the graphite QDs can attract more light-induced free holes in the graphene film. Such carrier transfer is known to enable more effective charge separation in graphite QDs and consequently suppress the electron-hole recombination [122,127]. Figure $10 \mathrm{~d}$ shows PC as a function of drain-source voltage $\left(V_{D S}\right)$ under different optical powers, showing a linear dependence on bias. Here, the photoconduction gain is enhanced by the recycling of holes through the graphene channel within the lifetime of the trapped electrons.

(a)



(c)



(b)

Graphene Graphite QD

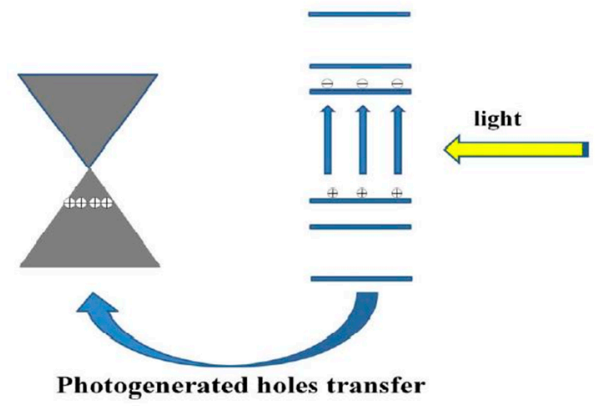

(d)

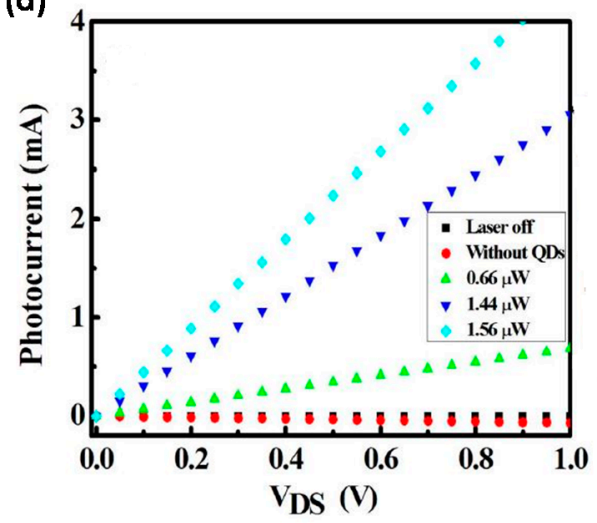

Figure 10. (a) Schematic of all carbon-based PD; (b) Under light illumination, the hole can transfer from graphite quantum dots to graphene sheets. The photo-generated electrons are trapped in graphite quantum dots; (c) Transfer characteristics of graphene transistors with and without the addition of graphite QDs on the graphene sheet; (d) Photocurrent of all carbon-based photodetectors for different optical powers as functions of drain-source voltage $\left(V_{D S}\right)$, showing a linear dependence on bias. The PC for the pure graphene device without graphite quantum dots is also shown here, which indicates a negligible effect. Reproduced with permission for Figure 10a-d from 2013 Scientific Reports [81].

Graphene was hybridized with graphene QDs on a rippled poly(dimethylsiloxane) substrate to fabricate stretchable PD [82], whose PC strongly depended on the external strain. The PC gradually decreased as the strain increased due to the reduction of light absorption resulting from multiple reflections of the photons in the ripple. The PD showed $2.8 \times 10^{3}$ photoconductive gain in the UV range. 
Graphene/graphene QDs/graphene PD was also fabricated to form hybrid-type PD that operates over a wide spectral range from UV to NIR $[84,85]$. This PD showed $\sim 0.5 \mathrm{~A} / \mathrm{W} \mathrm{R}, 10^{11} \mathrm{~cm} \cdot \mathrm{Hz}^{1 / 2} / \mathrm{W} D^{*}$, $\sim 95 \mathrm{~dB}$ linear dynamic range (LDR), and $100 \mu$ s response time. Recently, PDs composed of silica NPs and graphene QDs as donors and acceptors were well operated based on Förster resonance energy transfer (FRET) mechanism, as shown in Figure 11a-c [86]. Under reverse bias at $532 \mathrm{~nm}$, the $R$ of the FRET system was more than three times greater than that of the PD containing only graphene QDs, as shown in Figure 11d. This performance improvement was interpreted by the network-like current paths formed by the graphene QDs on the silica NPs and easy transfer of the carriers generated from the silica NPs into the graphene QD due to their close attachment. The PD further exhibited asymmetric and nonlinear current-voltage characteristics, which was attributed to the tunneling of the charge carriers through the available density of graphene QDs between the metallic graphene layers.

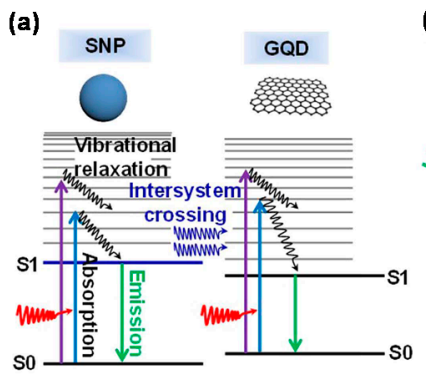

(b)


Figure 11. (a) Band structures of silica NPs (SNP) and graphene QD (GQD). Possible absorption/emission/transfer processes are described. Here, S0 and S1 indicate ground and lowest excited states, respectively. SNPs are highly absorptive, especially in the range of the emission spectrum of GQDs; (b) A schematic of a typical Förster resonance energy transfer (FRET) system composed of SNPs and GQDs as donors and acceptors, respectively. Photo-excited electron-hole pairs occupy mostly surface states of SNPs, thereby making it easy for the energy to be transferred to adjacent GQDs. The distance at which the FRET efficiency drops to $50 \%$ is defined as the Forster radius $\left(R_{0}\right)$, typically in the range of 1-10 nm. The use of one-atom-thick GQDs for acceptors can minimize $R_{0}$ and maximize the contacting area of the acceptors and the donors; (c) Schematic of the PD structure composed of the FRET system sandwiched between single-layer graphene sheets; (d) Responsivities of SNPs, GQDs, and SNPs/GQDs hybrid as functions of bias voltage, excited at $532 \mathrm{~nm}$. Reproduced with permission for Figure 11a-d from 2016 Scientific Reports [86].

\subsection{Graphene/One-Dimensional Carbon}

CNTs can be metallic or semiconducting depending on their respective chiral vector [128]. Metallic CNTs are particularly useful as transparent conductors, whilst semiconducting CNTs are promising candidates as channel materials in FETs for electronic applications. CNTs are also very useful for new optoelectronic devices due to their inherent excellent optical properties such as direct bandgap nature, strong light absorption/emission, and high radiation/fluorescence lifetimes. Recently, there has been a report of a broadband phototransistor made of a graphene film on the ultrathin layer of single-wall CNTs [87]. In this device, the electrons move to the graphene channel and the holes 
are trapped in the CNTs. The trapped holes effectively modulate the channel conductance, leading to a continuous negative shift of the Dirac point voltage with increasing the illumination intensity. In addition, the built-in potential can be effectively tuned by adjusting the graphene Fermi level, thereby controlling PC and $R$ under different back-gate voltages. The $R$ was shown to be $\sim 120 \mathrm{~A} / \mathrm{W}$ and $\sim 40 \mathrm{~A} / \mathrm{W}$ at 650 and $1550 \mathrm{~nm}$, respectively.

More recently, there has been a report on novel broadband graphene/CNT thin film photodiode [88], where the optical carriers near the interface are separated by built-in potential under illumination. The electrons and holes are then collected by each electrode, resulting in a PC in the external circuit. The $I_{\text {light }} / I_{\text {dark }}$ ratio, $R$, and specific $D^{*}$ of the PD are $240,0.21 \mathrm{~A} / \mathrm{W}$, and $4.87 \times 10^{10}$ Jones, respectively, much larger than other CNTs-based PDs. The PD also exhibited a fast response rate of $68 / 78 \mu$ s rise/fall times and $5400 \mathrm{~Hz} 3 \mathrm{~dB}$ bandwidth.

\section{Graphene/2D Layered Semiconductors}

The van der Waals interaction between neighboring layers without dangling bonds in 2D materials allows for their integration with other materials, including graphene, to form a variety of planar or vertical functional heterostructures with fundamentally different properties. As a prototype geometry, 2D layered semiconductors such as InSe [89], $\mathrm{WS}_{2}$, [90], $\mathrm{MoTe}_{2}$ [91], and graphene were used as the light absorbing medium and both-side electrodes, respectively, to fabricate planar metal-semiconductor-metal-type phototransistors. Compared to metal electrodes, the graphene electrode has the advantage of tuning the Schottky barrier between the graphene and the 2D semiconductors by controlling the Fermi level of graphene. Therefore, the photoresponse characteristics can be adjusted by electrostatic gating or optical input control. An ideal ohmic contact between the graphene and the 2D layered semiconductor can be achieved by tuning the Schottky barrier.

Recently, the planar graphene/n-InSe/graphene van der Waals heterostructures showed high $\mathrm{R}$ of $4 \times 10^{3} \mathrm{~A} \cdot \mathrm{W}^{-1}$ and fast rise/fall times of $1 / 10 \mathrm{~ms}$ [89]. The electrons move from graphene to n-InSe due to the higher work function of graphene, resulting in an accumulation layer at the graphene/n-InSe interface in equilibrium for a wide range of applied gate voltages. This study provides an innovative device architecture that enables access to fast electronic speed and high broadband spectral response. In another study, abnormal dependence of the $R$ on incident light power was observed in graphene/ $\mathrm{WS}_{2}$ /graphene heterostructure device [90]. In this device, the $R$ increases as the optical power increases at $V_{g}=0 \mathrm{~V}$ (off state), considered to be due to an efficient photo-induced charge transfer process in which electrons reside in the graphene while the holes are located at $\mathrm{WS}_{2}$. On the other hand, at $V_{g}=30 \mathrm{~V}$ (on state), the $R$ decreases as the optical power increases. When on state in the phototransistor, the photo-gating effect can increase the Fermi level and reduce the contact resistance. As a result, the influence of illumination on the Fermi level of graphene is reduced, thereby causing different power dependence of $R$.

In device structures dominated by photogating effects, 2D semiconductor serves as a medium for harvesting light, whereas graphene serves as a conduction channel for carrier transport and circulation. Recently, mechanically exfoliated graphene- $\mathrm{MoS}_{2}$ hybrid heterostructure phototransistors exhibited a high $R$ of $5 \times 10^{8}$ and $1 \times 10^{10} \mathrm{~A} \cdot \mathrm{W}^{-1}$ at $130 \mathrm{~K}$ and room temperature, respectively [22]. Here, the photogenerated holes under illumination are trapped in $\mathrm{MoS}_{2}$ by local conditions, and the electrons are transferred to the graphene with the help of the gate electric field, resulting in high $R$. On the other hand, the trapped holes act as local gates, thereby causing a significant photogating effect on graphene through capacitive coupling. Eventually, the response time is slow because of the long life of the trapped holes. In another approach, a similar phototransistor was fabricated using CVD-induced graphene and $\mathrm{MoS}_{2}$ [92]. This hybrid heterostructure device showed a relatively low response of $\sim 1.2 \times 10^{7} \mathrm{~A} \cdot \mathrm{W}^{-1}$ due to the low carrier mobility of CVD-graphene and very slow response times of several-hundred seconds, but seemed to be better suited for practical applications by easy preparation in large areas. 
Recently, graphene/transition metal dichalcogenide (TMD) heterostructures have also exhibited significant functionalities in the photodiode type. Carrier generation, separation, and transport processes were shown to be adjusted by easily modulating the Fermi level of graphene and the height of the Schottky barrier in graphene/TMD/graphene vertically-stacked heterostructures. For instance, graphene $/ \mathrm{WS}_{2}$ / graphene stack heterostructures were useful for efficient light-matter interactions, leading to improved photon absorption and electron-hole generation [93]. Scanning Photomicroscopy PC mapping showed that the PC generation occurred primarily in regions of heterogeneous structures with asymmetric potentials. In addition, $R$ increases from $\sim 10^{-2}$ to $\sim 10^{-1} \mathrm{~A} \cdot \mathrm{W}^{-1}$ by integrating plasmonic metal nanostructures and heterostructures to improve the light absorption. It is worth noting that these results can be used for designing the dual-gate-type graphene/WS $2 /$ graphene heterostructure to control the polarity and amplitude of the PC by adjusting the direction and intensity of the built-in electric field [94]. A typical heterostructure of graphene/WSe 2 /graphene employing $2.2 \mathrm{~nm}$ trilayer $\mathrm{WSe}_{2}$, as shown in Figure 12a [95], exhibits fast response (5.5 ps) and high internal quantum efficiency $(70 \%)$, as shown in Figure $12 \mathrm{~b}, \mathrm{c}$. Further improvement of $7.3 \%$ in the external quantum efficiency was achieved by using optical waveguides and cavity or plasmon nanostructures in the TMD layer to improve light-matter interactions [129-131].
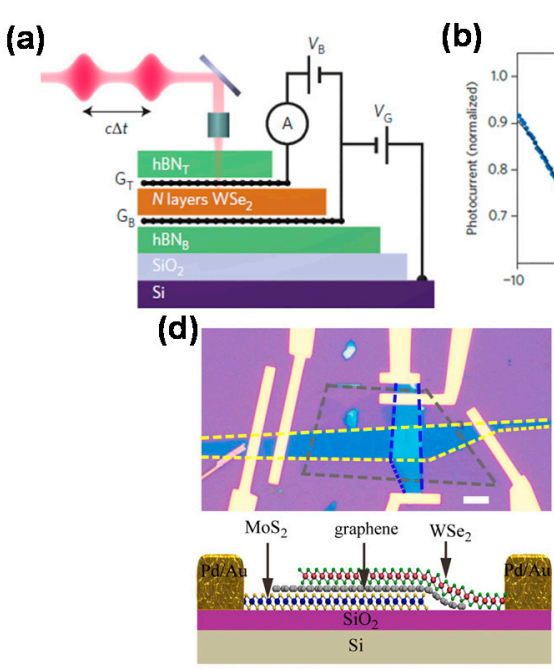

(b)

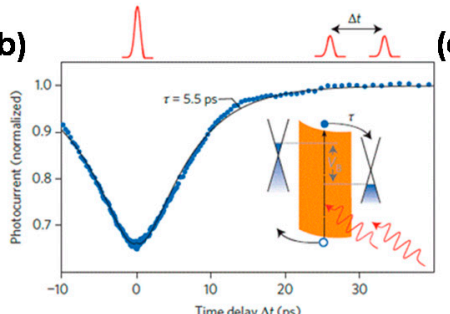

(e)

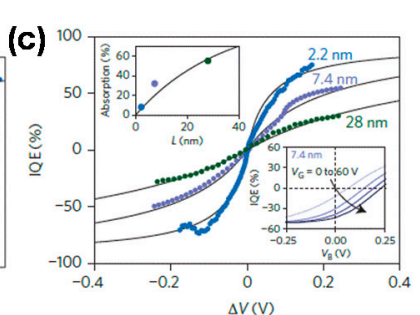
$\Delta V(V)$

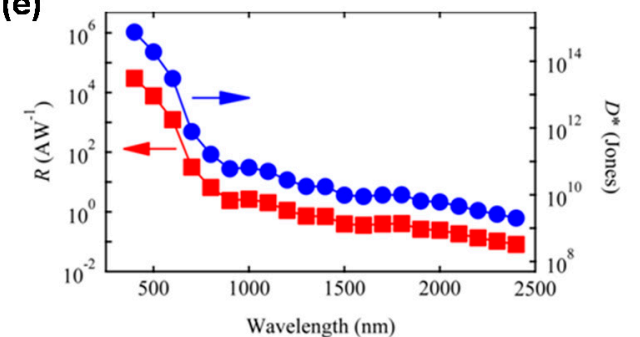

Figure 12. (a) Schematic illustration of the experimental time-resolved photocurrent set-up and cross-sectional view of the graphene/WSe 2 /graphene heterostructure; (b) Photocurrent as a function of time delay between two pulses; (c) IQE as a function of potential drop across theWSe $\mathrm{e}_{2}$ layer $\Delta V$ for devices with channel length $=2.2,7.4$, and $28 \mathrm{~nm}$. Reproduced with permission for Figure 12a-c from 2016 Nature Nanotechnology [95]; (d) Top: optical image of a device fabricated based on van der Waals-assembled $\mathrm{MoS}_{2}$-graphene-WSe 2 . Bottom: schematic side view of the heterostructure; (e) Responsivity $(R)$ and specific detectivity $\left(D^{*}\right)$ of a typical device for wavelengths ranging from 400 to $2400 \mathrm{~nm}$. The device was tested in ambient air at $V_{D S}=1 \mathrm{~V}$ and $V_{g}=0 \mathrm{~V}$. Reproduced with permission for Figure 12d,e from 2016 Nano Letters [100].

As another approach, relatively-low- $R$ photodiodes were fabricated by integrating graphene with TMD stacked semiconductors such as $\mathrm{MoS}_{2}, \mathrm{MoTe}_{2}$, and $\mathrm{WSe}_{2}$ [96-99]. Here, the gate tunable mismatch of graphene and semiconductor Fermi levels allows tunable Schottky junctions, thereby showing adjustable rectification behaviors and photovoltaic response characteristics. Interestingly, the detection range of the devices can be extended enough to overcome band edge absorption limits of the semiconductor, useful for the internal photoemission in graphene. Especially, the graphene/MoS Schottky junction photodiode exhibited unique optical response over a wide spectral range from 400 to $1500 \mathrm{~nm}$ [96]. Maximum $R$ values of $0.52 \mathrm{~A} \cdot \mathrm{W}^{-1}$ at $590 \mathrm{~nm} / 1.26 \mathrm{~A} \cdot \mathrm{W}^{-1}$ at $1440 \mathrm{~nm}$ were obtained when operating in the energy gap excitation mode/when internal light emission dominated the 
PC generation in graphene, respectively. On the other hand, metal-insulator-semiconductor-like photodiodes with an insulator layer between graphene and $\mathrm{MoS}_{2}$ showed improved current rectification and higher current flow compared to 2D-based metal-semiconductor diodes and $\mathrm{p}-\mathrm{n}$ junctions based on TMDs [97]. This was attributed to the formation of a multi-layered semiconductor, resulting in the carrier tunneling in the forward bias and the depressed carrier tunneling in the reverse bias. Figure $12 \mathrm{~d}$ shows the vertical tuning of the $\mathrm{WSe}_{2} /$ graphene $/ \mathrm{MoS}_{2}$ gate tunable rectification behavior and the broadband response ranging from 400 to $2400 \mathrm{~nm}$. [100]. The device exhibits high $R$ and $D^{*}$ of up to $10^{5} \mathrm{~A} \cdot \mathrm{W}^{-1}$ and $10^{15}$ Jones in the visible range, respectively, but they sharply decrease to $10^{-1} \mathrm{~A} \cdot \mathrm{W}^{-1}$ and $10^{9}$ Jones at $2400 \mathrm{~nm}$ IR wavelength, as shown in Figure 12e. This unique response to different wavelengths can be understood as follows. In the visible light region where the incident photon energy is greater than the bandgap of the TMD, the incident light can be absorbed by all three materials ( $\mathrm{WSe}_{2}$, graphene, and $\mathrm{MoS}_{2}$ ), resulting in a large number of photocarriers, contributing to significant increase of PC. However, when the IR light having energy smaller than the band gap of $\mathrm{WSe}_{2}$ is irradiated, only graphene can absorb light, resulting in very low PC. These results suggest that the van der Waals junctions based on 2D materials are very promising in future critical optoelectronic device applications.

\section{Conclusions and Outlook}

Graphene/semiconductor hybrid heterostructures showed their tremendous potential for PD applications. Particular attention was paid to several important issues related to device design, device performance, and processing technology to enhance figure-of-merit parameters of the PDs. By the optimization through various approaches, the PDs typically showed some new features that could open up the way to many conventional and advanced applications. The work function, surface resistance, and optical transparency of the graphene TCEs were successfully tuned by adjusting the number of layers, chemical doping, photo-induced doping, or electric field gating doping, which strongly affected the performance of the PDs. To meet the requirements for the practical applications of the PDs, some of the properties of the sensing materials should be optimized. Because the heterogeneity of the nanostructured materials can greatly affect the uniformity of the device performance, more precise control of their morphology, crystallinity, and orientation is highly needed. Some emerging methods such as plasmonic technology and integration of optical waveguides/micro cavities are also useful for improving the photo-material interactions, resulting in the increase of the light absorption. In particular, special efforts should be made for high response speed of the PDs by increasing the charge carrier mobility of the sensing materials or introducing a vertical electric field for the transfer and separation of photo-carriers. Broadband, spectrally selective, or flexible PDs should also be developed for specific applications. In addition to the improvements of the figure-of-merit parameters, long-term reliability and durability, environmentally-friendly and cost-effective machining technologies, large-scale production and consolidation are also important issues for various applications of the PDs in upcoming new situations.

Funding: This research was funded by Basic Science Research Program through the National Research Foundation of Korea (NRF) funded by the Ministry of Science, ICT \& Future Planning: NRF-2017R1A2B3006054.

Conflicts of Interest: The authors declare no competing financial interest.

\section{References}

1. Jansen-van Vuuren, R.D.; Armin, A.; Pandey, A.K.; Burn, P.L.; Meredith, P. Organic photodiodes: The future of full color detection and image sensing. Adv. Mater. 2016, 28, 4766-4802. [CrossRef] [PubMed]

2. Zhao, Z.; Liu, J.; Liu, Y.; Zhu, N. High-speed photodetectors in optical communication system. J. Semicond. 2017, 38, 121001, doi:10.1088/1674-4926/38/12/121001. [CrossRef] 
3. Marcellis, A.D.; Palange, E. Differential measurements of light power variations through Si photodiodes in a bridge configuration for high-sensitivity chemical/biological optical sensing. Sens. Actuators B 2011, 156, 893-898. [CrossRef]

4. Lee, H.; Han, G.; Kim, M.; Ahn, H.-S.; Lee, H. High mechanical and trbological stability of an elastic ultrathin overcoating layer for flexible silver nanowire films. Adv. Mater. 2015, 27, 2252-2259. [CrossRef] [PubMed]

5. Kholmanov, I.N.; Magnuson, C.W.; Aliev, A.E.; Li, H.; Zhang, B.; Suk, J.W.; Zhang, L.L.; Peng, E.; Mousavi, S.H.; Khanikaev, A.B.; et al. Improved electrical conductivity of graphene films integrated with metal nanowires. Nano Lett. 2012, 12, 5679-5683. [CrossRef] [PubMed]

6. Kurra, N.; Wang, R.; Alshareef, H.N. All conducting polymer electrodes for asymmetric solid-state supercapacitors. J. Mater. Chem. A 2015, 3, 7368-7374. [CrossRef]

7. Habisreutinger, S.N.; Nicholas, R.J.; Snaith, H.J. Carbon nanotubes in perovskite solar cells. Adv. Energy Mater. 2017, 7, 1601839, doi:10.1002/aenm.201601839. [CrossRef]

8. Jeon, I.; Yoon, J.; Ahn, N.; Atwa, M.; Delacou, C.; Anisimov, A.; Kauppinen, E.I.; Choi, M.; Maruyama, S.; Matsuo, Y. Carbon nanotubes versus graphene as flexible transparent electrodes in inverted perovskite solar cells. J. Phys. Chem. Lett. 2017, 8, 5395-5401. [CrossRef] [PubMed]

9. Liu, C.-H.; Chang, Y.-C.; Norris, T.; Zhong, Z. Graphene photodetectors with ultra-broadband and high responsivity at room temperature. Nat. Nanotechnol. 2014, 9, 273-278. [CrossRef] [PubMed]

10. Schall, D.; Porschatis, C.; Otto, M.; Neumaier, D. Graphene photodetectors with a bandwidth $>76 \mathrm{GHz}$ fabricated in a 6" wafer process line. J. Phys. D Appl. Phys. 2017, 50, 124004. [CrossRef]

11. Wang, F.; Zhang, Y.; Tian, C.; Girit, C.; Zettl, A.; Crommie, M.; Shen, Y.R. Gate-variable optical transitions in graphene. Science 2008, 320, 206-209. [CrossRef] [PubMed]

12. Liu, H.; Liu, Y.; Zhu, D. Chemical doping of graphene. J. Mater. Chem. 2011, 21, 3335-3345. [CrossRef]

13. Liu, Z.; Lau, S.P.; Yan, F. Functionalized graphene and other two-dimensional materials for photovoltaic devices: Device design and processing. Chem. Soc. Rev. 2015, 44, 5638-5679. [CrossRef] [PubMed]

14. Koppens, F.H.L.; Mueller, T.; Avouris, P.; Ferrari, A.C.; Vitiello, M.S.; Polini, M. Photodetectors based on graphene, other two-dimensional materials and hybrid systems. Nat. Nanotechnol. 2014, 9, 780-793. [CrossRef] [PubMed]

15. Sun, Z.; Chang, H. Graphene and graphene-like two-dimensional materials in photodetection: Mechanisms and methodology. ACS Nano 2014, 8, 4133-4156. [CrossRef] [PubMed]

16. Xie, C.; Mak, C.; Tao, X.; Yan, F. Photodetectors based on two-dimensional layered materials beyond graphene. Adv. Funct. Mater. 2017, 27, 1603886. [CrossRef]

17. Xia, F.; Mueller, T.; Lin, Y.-M.; Valdes-Garcia, A.; Avouris, P. Ultrafast graphene photodetector. Nat. Nanotechnol. 2009, 4, 839-843. [CrossRef] [PubMed]

18. Bao, W.; Jing, L.; Velasco, J., Jr.; Lee, Y.; Liu, G.; Tran, D.; Standley, B.; Aykol, M.; Cronin, S.B.; Smirnov, D.; et al. Stacking-dependent band gap and quantum transport in trilayer graphene. Nat. Phys. 2011, 7, 948-952. [CrossRef]

19. Sonde, S.; Giannazzo, F.; Raineri, V.; Yakimova, R.; Huntzinger, J.-R.; Tiberj, A.; Camassel, J. Electrical properties of the graphene/4H-SiC (0001) interface probed by scanning current spectroscopy. Phys. Rev. B 2009, 80, 241406, doi:10.1103/PhysRevB.80.241406. [CrossRef]

20. Song, Y.; Li, X.; Mackin, C.; Zhang, X.; Fang, W.; Palacios, T.; Zhu, H.; Kong, J. Role of interfacial oxide in high-efficiency graphene-silicon Schottky barrier solar cells. Nano Lett. 2015, 15, 2104-2110. [CrossRef] [PubMed]

21. Konstantatos, G.; Badioli, M.; Gaudreau, L.; Osmond, J.; Bernechea, M.; Arquer, F.P.G.D.; Gatti, F.; Koppens, F.H.L. Hybrid graphene-quantum dot phototransistors with ultrahigh gain. Nat. Nanotechnol. 2012, 7, 363-368. [CrossRef] [PubMed]

22. Roy, K.; Padmanabhan, M.; Goswami, S.; Sai, T.P.; Ramalingam, G.; Raghavan, S.; Ghosh, A. Graphene-MoS 2 hybrid structures for multifunctional photoresponsive memory devices. Nat. Nanotechnol. 2013, 8, 826-830. [CrossRef] [PubMed]

23. Li, X.; Chen, W.; Zhang, S.; Wu, Z.; Wang, P.; Xu, Z.; Chena, H.; Yin, W.; Zhong, H.; Lin, S. 18.5\% efficient graphene/GaAs vander Waals heterostructure solar cell. Nano Energy 2015, 16, 310-319. [CrossRef]

24. An, X.; Liu, F.; Jung, Y.J.; Kar, S. Tunable graphene-silicon heterojunctions for ultrasensitive photodetection. Nano Lett. 2013, 13, 909-916. [CrossRef] [PubMed] 
25. Amirmazlaghani, M.; Raissi, F.; Habibpour, O.; Vukusic, J.; Stake, J. Graphene-Si Schottky IR photodetectors. IEEE J. Quantum Electron. 2013, 49, 589-594. [CrossRef]

26. An, Y.; Behnam, A.; Pop, E.; Ural, A. Metal-semiconductor-metal photodetectors based on graphene/p-type silicon Schottky junctions. Appl. Phys. Lett. 2013, 102, 013110. [CrossRef]

27. Zhu, M.; Zhang, L.; Li, X.; He, Y.; Li, X.; Guo, F.; Zang, X.; Wang, K.; Xie, D.; Li, X.; et al. TiO 2 enhanced ultraviolet detection based on a graphene/Si Schottky diode. J. Mater. Chem. A 2015, 3, 8133-8138. [CrossRef]

28. Wan, X.; Xu, Y.; Guo, H.; Shehzad, K.; Ali, A.; Liu, Y.; Yang, J.; Dai, D.; Lin, C.-T.; Liu, L.; et al. A self-powered high-performance graphene/silicon ultraviolet photodetector with ultra-shallow junction: Breaking the limit of silicon? NPJ 2D Mater. Appl. 2017, 1, 4. [CrossRef]

29. Huang, K.; Yan, Y.; Li, K.; Khan, A.; Zhang, H.; Pi, X.; Yu, X.; Yang, D. High and fast response of a graphene-silicon photodetector coupled with 2D fractal platinum nanoparticles. Adv. Opt. Mater. 2017, 6, 1700793, doi:10.1002/adom.201700793. [CrossRef]

30. Xiang, D.; Han, C.; Hu, Z.; Lei, B.; Liu, Y.; Wang, L.; Hu, W.P.; Chen, W. Surface transfer doping-induced, high-performance graphene/silicon Schottky junction-based, self-powered photodetector. Small 2015, 11, 4829-4836. [CrossRef] [PubMed]

31. Li, X.; Zhu, M.; Du, M.; Lv, Z.; Zhang, L.; Li, Y.; Yang, Y.; Yang, T.; Li, X.; Wang, K.; et al. High detectivity graphene-silicon heterojunction photodetector. Small 2016, 12, 595-601. [CrossRef] [PubMed]

32. Bartolomeo, A.D.; Luongo, G.; Giubileo, F.; Funicello, N.; Niu, G.; Schroeder, T.; Lisker, M.; Lupina, G. Hybrid graphene/silicon Schottky photodiode with intrinsic gating effect. 2D Mater. 2017, 4, 025075. [CrossRef]

33. Riazimehr, S.; Kataria, S.; Bornemann, R.; Bolívar, P.H.; Ruiz, F.J.G.; Engström, O.; Godoy, A.; Lemme, M.C. High photocurrent in gated graphene-silicon hybrid photodiodes. ACS Photonics 2017, 4, 1506-1514. [CrossRef] [PubMed]

34. Shen, J.; Liu, X.; Song, X.; Li, X.; Wang, J.; Zhou, Q.; Luo, S.; Feng, W.; Wei, X.; Lu, S.; et al. High-performance Schottky heterojunction photodetector with directly grown graphene nanowalls as electrodes. Nanoscale 2017, 9, 6020-6025. [CrossRef] [PubMed]

35. Kim, J.; Joo, S.S.; Lee, K.W.; Kim, J.H.; Shin, D.H.; Kim, S.; Choi, S.-H. Near-ultraviolet-sensitive graphene/porous silicon photodetectors. ACS Appl. Mater. Interfaces 2014, 6, 20880-20886. [CrossRef] [PubMed]

36. Luo, L.-B.; Zeng, L.-H.; Xie, C.; Yu, Y.-Q.; Liang, F.-X.; Wu, C.-Y.; Wang, L.; Hu, J.-G. Light trapping and surface plasmon enhanced high-performance NIR photodetector. Sci. Rep. 2014, 4, 3914. [CrossRef] [PubMed]

37. Choi, S.-H. Graphene-based vertical-junction diodes and applications. J. Korean Phys. Soc. 2017, 71, 311-318. [CrossRef]

38. Shin, D.H.; Kim, S.; Kim, J.M.; Jang, C.W.; Kim, J.H.; Lee, K.W.; Kim, J.; Oh, S.D.; Lee, D.H.; Kang, S.S.; et al. Graphene/Si-quantum-dot heterojunction diodes showing high photosensitivity compatible with quantum confinement effect. Adv. Mater. 2015, 27, 2614-2620. [CrossRef] [PubMed]

39. Shin, D.H.; Jang, C.W.; Kim, J.H.; Kim, J.M.; Lee, H.S.; Seo, S.W.; Kim, S.; Choi, S.-H. Enhancement of efficiency and long-term stability in graphene/Si-quantum-dot heterojunction photodetectors by employing bis(trifluoromethanesulfonyl)-amide as a dopant for graphene. J. Mater. Chem. C 2014, 5, 12737-12743. [CrossRef]

40. Yu, T.; Wang, F.; Xu, Y.; Ma, L.; Pi, X.; Yang, D. Graphene coupled with silicon quantum dots for high-performance bulk-silicon-based schottky-junction photodetectors. Adv. Mater. 2016, 28, 4912-4919. [CrossRef] [PubMed]

41. Ni, Z.; Ma, L.; Du, S.; Xu, Y.; Yuan, M.; Fang, H.; Wang, Z.; Xu, M.; Li, D.; Yang, J.; et al. Plasmonic silicon quantum dots enabled high-sensitivity ultrabroadband photodetection of graphene-based hybrid phototransistors. ACS Nano 2017, 11, 9854-9862. [CrossRef] [PubMed]

42. Lee, C.-J.; Kang, S.-B.; Cha, H.-G.; Won, C.-H.; Hong, S.-K.; Cho, B.-J.; Park, H.; Lee, J.-H.; Hahm, S.-H. GaN metal-semiconductor-metal UV sensor with multi-layer graphene as Schottky electrodes. Jpn. J. Appl. Phys. 2015, 54, 06FF08, doi:10.7567/JJAP.54.06FF08. [CrossRef]

43. Babichev, A.V.; Zhang, H.; Lavenus, P.; Julien, F.H.; Egorov, A.Y.; Lin, Y.T.; Tu, L.W.; Tchernycheva, M. GaN nanowire ultraviolet photodetector with a graphene transparent contact. Appl. Phys. Lett. 2013, 103, 201103, doi:10.1063/1.4829756. [CrossRef] 
44. Luo, L.-B.; Chen, J.-J.; Wang, M.-Z.; Hu, H.; Wu, C.-Y.; Li, Q.; Wang, L.; Huang, J.-A.; Liang, F.-X. Near-infrared light photovoltaic detector based on GaAs nanocone array/monolayer graphene Schottky junction. Adv. Funct. Mater. 2014, 24, 2794-2800. [CrossRef]

45. Bartolomeo, A.D.; Giubileo, F.; Luongo, G.; Iemmo, L.; Martucciello, N.; Niu, G.; Fraschke, M.; Skibitzki, O.; Schroeder, T.; Lupina, G. Tunable Schottky barrier and high responsivity in graphene/Si nan optoelectronic device. 2D Mater. 2017, 4, 015024, doi:10.1088/2053-1583/4/1/015024. [CrossRef]

46. Luo, L.-B.; Hu, H.; Wang, X.-H.; Lu, R.; Zou, Y.-F.; Yu, Y.-Q.; Liang, F.-X. A graphene/GaAs near-infrared photodetector enabled by interfacial passivation with fast response and high sensitivity. J. Mater. Chem. C 2015, 3, 4723-4728. [CrossRef]

47. Liu, J.; Lu, R.; Xu, G.; Wu, J.; Thapa, P.; Moore, D. Development of a seedless floating growth process in solution for synthesis of crystalline $\mathrm{ZnO}$ micro/nanowire arrays on graphene: Towards high-performance nanohybrid ultraviolet photodetectors. Adv. Funct. Mater. 2013, 23, 4931-4948. [CrossRef]

48. Boruah, B.D.; Misra, A. ZnO quantum dots and graphene based heterostructure for excellent photoelastic and highly sensitive ultraviolet photodetector. RSC. Adv. 2015, 5, 90838-90846. [CrossRef]

49. Guo, W.; Xu, S.; Wu, Z.; Wang, N.; Loy, M.M.T.; Du, S. Oxygen-assisted charge transfer between ZnO quantum dots and graphene. Small 2013, 9, 3031-3036. [CrossRef] [PubMed]

50. Dang, V.Q.; Trung, T.Q.; Kim, D.-I.; Duy, L.T.; Hwang, B.-U.; Lee, D.-W.; Kim, B.-Y.; Toan, L.D.; Lee, N.-E. Ultrahigh responsivity in graphene-ZnO nanorod hybrid UV photodetector. Small 2015, 11, 3054-3065. [CrossRef] [PubMed]

51. Dang, V.Q.; Trung, T.Q.; Duy, L.T.; Kim, B.-Y.; Siddiqui, S.; Lee, W.; Lee, N.-E. High-performance flexible ultraviolet (UV) phototransistor using hybrid channel of vertical $\mathrm{ZnO}$ nanorods and graphene. ACS Appl. Mater. Interfaces 2015, 7, 11032-11040. [CrossRef] [PubMed]

52. Boruah, B.D.; Mukherjee, A.; Sridhar, S.; Misra, A. Highly dense ZnO nanowires grown on graphene foam for ultraviolet photodetection. ACS Appl. Mater. Interfaces 2015, 7, 10606-10611. [CrossRef] [PubMed]

53. Biroju, R.K.; Tilak, N.; Rajender, G.; Dhara, S.; Giri, P.K. Catalyst free growth of ZnO nanowires on graphene and graphene oxide and its enhanced photoluminescence and photoresponse. Nanotechnology 2015, 26, 145601, doi:10.1088/0957-4484/26/14/145601. [CrossRef] [PubMed]

54. Boruah, B.D.; Ferry, D.B.; Mukherjee, A.; Misra, A. Few-layer graphene/ZnO nanowires based high performance UV photodetector. Nanotechnology 2015, 26, 235703, doi:10.1088/0957-4484/26/23/235703. [CrossRef] [PubMed]

55. Shao, D.; Gao, J.; Chow, P.; Sun, H.; Xin, G.; Sharma, P.; Lian, J.; Koratkar, N.A.; Sawyer, S. Organic-inorganic heterointerfaces for ultrasensitive detection of ultraviolet light. Nano Lett. 2015, 15, 3787-3792. [CrossRef] [PubMed]

56. Gong, M.; Liu, Q.; Cook, B.; Kattel, B.; Wang, T.; Chan, W.-L.; Ewing, D.; Casper, M.; Stramel, A.; Wu, J.Z. All-printable $\mathrm{ZnO}$ quantum dots/graphene van der Waals heterostructures for ultrasensitive detection of ultraviolet light. ACS Nano 2017, 11, 4114-4123. [CrossRef] [PubMed]

57. Nie, B.; Hu, J.-G.; Luo, L.-B.; Xie, C.; Zeng, L.-H.; Lv, P.; Li, F.-Z.; Jie, J.-S.; Feng, M.; Wu, C.-Y.; et al. Monolayer graphene film on $\mathrm{ZnO}$ nanorod array for high-performance Schottky junction ultraviolet photodetectors. Small 2013, 9, 2872-2879. [CrossRef] [PubMed]

58. Wu, Z.; Li, X.; Zhong, H.; Zhang, S.; Wang, P.; Kim, T.-H.; Kwak, S.S.; Liu, C.; Chen, H.; Kim, S.-W.; et al. Graphene/h-BN/ZnO van der Waals tunneling heterostructure based ultraviolet photodetector. Opt. Express 2015, 23, 236116, doi:10.1364/OE.23.018864. [CrossRef] [PubMed]

59. Lee, S.; Lee, Y.; Kim, D.Y.; Song, E.B.; Kim, S.M. Back-gate tuning of Schottky barrier height in graphene/zinc-oxide photodiodes. Appl. Phys. Lett. 2013, 102, 242114. [CrossRef]

60. Liu, S.; Liao, Q.; Lu, S.; Zhang, Z.; Zhang, G.; Zhang, Y. Strain modulation in graphene/ZnO nanorod film Schottky junction for enhanced photosensing performance. Adv. Funct. Mater. 2016, 26, 1347-1353. [CrossRef]

61. Cheng, C.-C.; Zhan, J.-Y.; Liao, Y.-M.; Lin, T.-Y.; Hsieh, Y.-P.; Chen, Y.-F. Self-powered and broadband photodetectors based on graphene/ZnO/silicon triple junctions. Appl. Phys. Lett. 2016, 109, 053501, doi:10.1063/1.4960357. [CrossRef]

62. Zhang, T.-F.; Wu, G.-A.; Wang, J.-Z.; Yu, Y.-Q.; Zhang, D.-Y.; Wang, D.D.; Jiang, J.-B.; Wang, J.-M.; Luo, L.-B. A sensitive ultraviolet light photodiode based on graphene-on-zinc oxide Shcottky junction. Nanophotonics 2017, 6, 1073-1081. [CrossRef] 
63. Liu, H.; Sun, Q.; Xing, J.; Zheng, Z.; Zhang, Z.; Lu, Z.; Zhao, K. Fast and enhanced broadband photoresponse of a $\mathrm{ZnO}$ nanowire array/reduced graphene oxide film hybrid photodetector from the visible to the near-infrared range. ACS Appl. Mater. Interfaces 2015, 7, 6645-6651. [CrossRef] [PubMed]

64. Boruah, B.D.; Mukherjee, A.; Misra, A. Sandwiched assembly of ZnO nanowires between graphene layers for a self-powered and fast responsive ultraviolet photodetector. Nanotechnology 2016, 27, 095205. [CrossRef] [PubMed]

65. Sahatiya, P.; Jones, S.S.; Gomathi, P.T.; Badhulika, S. Flexible substrate based 2D ZnO (n)/graphene (p) rectifying junction as enhanced broadband photodetector using strain modulation. 2D Mater. 2017, 4, 025053, doi:10.1088/2053-1583/aa6534. [CrossRef]

66. Duan, L.; He, F.; Tian, Y.; Sun, B.; Fan, J.; Yu, X.; Ni, L.; Zhang, Y.; Chen, Y.; Zhang, W. Fabrication of self-powered fast-response ultraviolet photodetectors based on graphene/ZnO: Al nanorod-array-film structure with stable Schottky barrier. ACS Appl. Mater. Interfaces 2017, 9, 8161-8168. [CrossRef] [PubMed]

67. Li, J.; Lin, Y.; Lu, J.; Xu, C.; Wang, Y.; Shi, Z.; Dai, J. Single mode ZnO whispering-gallery submicron cavity and graphene improved lasing performance. ACS Nano 2015, 9, 6794-6800. [CrossRef] [PubMed]

68. Shi, X.; Liu, X.; Zeng, H. $\mathrm{ZrO}_{2}$ quantum dots/graphene phototransistors for deep UV detection. Mater. Res. Bull. 2017, 96, 458-462. [CrossRef]

69. Kong, W.-Y.; Wu, G.-A.; Wang, K.-Y.; Zhang, T.-F.; Zou, Y.-F.; Wang, D.-D.; Luo, L.-B. Graphene- $\beta-\mathrm{Ga}_{2} \mathrm{O}_{3}$ heterojunction for highly sensitive deep UV photodetector application. Adv. Mater. 2016, 28, 10725-10731. [CrossRef] [PubMed]

70. Ai, M.; Guo, D.; Qu, Y.; Cui, W.; Wu, Z.; Li, P.; Li, L.; Tang, W. Fast-response solar-blind ultraviolet photodetector with a graphene/ $\beta-\mathrm{Ga} 2 \mathrm{O} 3 /$ graphene hybrid structure. J. Alloys. Compd. 2017, 692, 634-638. [CrossRef]

71. Tan, W.-C.; Shih, W.-H.; Chen, Y.F. A highly sensitive graphene-organic hybrid photodetector with a piezoelectric substrate. Adv. Funct. Mater. 2014, 24, 6818-6825. [CrossRef]

72. Jang, S.; Hwang, E.; Lee, Y.; Lee, S.; Cho, J.H. Multifunctional graphene optoelectronic devices capable of detecting and storing photonic signals. Nano Lett. 2015, 15, 2542-2547. [CrossRef] [PubMed]

73. Liu, X.; Luo, X.; Nan, H.; Guo, H.; Wang, P.; Zhang, L.; Zhou, M.; Yang, Z.; Shi, Y.; Hu, W.; et al. Epitaxial ultrathin organic crystals on graphene for high-efficiency phototransistors. Adv. Mater. 2016, 28, 5200-5205. [CrossRef] [PubMed]

74. Lee, Y.; Kwon, J.; Hwang, E.; Ra, C.-H.; Yoo, W.J.; Ahn, J.-H.; Park, J.H.; Cho, J.H. High-performance perovskite-graphene hybrid photodetector. Adv. Mater. 2015, 27, 41-46. [CrossRef] [PubMed]

75. Dang, V.G.; Han, G.-S.; Trung, T.Q.; Duy, L.T.; Jin, W.U.; Hwang, B.U.; Jung, H.S.; Lee, N.E. Methylammonium lead iodide perovskite-graphene hybrid channels in flexible broadband phototransistors. Carbon 2016, 105, 353-361. [CrossRef]

76. Sun, Z.; Aigouy, L.; Chen, Z. Plasmonic-enhanced perovskite-graphene hybrid photodetectors. Nanoscale 2016, 8, 7377-7383. [CrossRef] [PubMed]

77. Chang, P.-H.; Liu, S.-Y.; Lan, Y.-B.; Tsai, Y.-C.; You, X.-Q.; Li, C.-S.; Huang, K.-Y.; Chou, A.-S.; Cheng, T.-C.; Wang, J.-K.; et al. Ultrahigh responsivity and detectivity graphene-perovskite hybrid phototransistors by sequential vapor deposition. Sci. Rep. 2017, 7, 46281. [CrossRef] [PubMed]

78. Xie, C.; Yan, F. Perovskite/poly(3-hexylthiophene)/graphene multiheterojunction phototransistors with ultrahigh gain in broadband wavelength region. ACS Appl. Mater. Interfaces 2017, 9, 1569-1576. [CrossRef] [PubMed]

79. Spina, M.; Lehmann, M.; Náfrádi, B.; Bernard, L.; Bonvin, E.; Gaál, R.; Magrez, A.; Forró, L.; Horváth, E. Microengineered $\mathrm{CH}_{3} \mathrm{NH}_{3} \mathrm{PbI}_{3}$ nanowire/graphene phototransistor for low-intensity light detection at room temperature. Small 2015, 11, 4824-4828. [CrossRef] [PubMed]

80. Kwak, D.-H.; Lim, D.-H.; Ra, H.-S.; Ramasamy, P.; Lee, J.-S. High performance hybrid graphene-CsPbBr $\mathrm{Pr}_{3}-\mathrm{xIx}$ perovskite nanocrystal photodetector. RSC Adv. 2016, 6, 65252-65256. [CrossRef]

81. Cheng, S.-H.; Weng, T.-M.; Lu, M.-L.; Tan, W.-C.; Chen, J.-Y.; Chen, Y.-F. All carbon-based photodetectors: An eminent integration of graphite quantum dots and two dimensional graphene. Sci. Rep. 2013, 3, 2694, doi:10.1038/srep02694. [CrossRef] [PubMed]

82. Chiang, C.-W.; Haider, G.; Tan, W.-C.; Liou, Y.-R.; Lai, Y.-C.; Ravindranath, R.; Chang, H.-T.; Chen, Y.-F. Highly stretchable and sensitive photodetectors based on hybrid graphene and graphene quantum dots. ACS Appl. Mater. Interfaces 2016, 8, 466-471. [CrossRef] [PubMed] 
83. Haider, G.; Roy, P.; Chiang, C.-W.; Tan, W.-C.; Liou, Y.-R.; Chang, H.-T.; Liang, C.-T.; Shih, W.-H.; Chen, Y.-F. Electrical-polarization-Induced ultrahigh responsivity photodetectors based on graphene and graphene quantum dots. Adv. Funct. Mater. 2016, 26, 620-628. [CrossRef]

84. Kim, C.O.; Hwang, S.W.; Kim, S.; Shin, D.H.; Kang, S.S.; Kim, J.M.; Jang, C.W.; Kim, J.H.; Lee, K.W.; Choi, S.-H.; et al. High-performance graphene-quantum-dot photodetectors. Sci. Rep. 2014, 4, 5603, doi:10.1038/srep05603. [CrossRef] [PubMed]

85. Choi, S.-H. Unique properties of graphene quantum dots and their applications in photonic/electronic devices. J. Phys. D Appl. Phys. 2017, 50, 103002. [CrossRef]

86. Kim, S.; Shin, D.H.; Kim, J.; Jang, C.W.; Kang, S.S.; Kim, J.M.; Kim, J.W.; Lee, D.H.; Kim, J.H.; Choi, S.-H.; et al. Energy transfer from an individual silica nanoparticle to graphene quantum dots and resulting enhancement of photodetector responsivity. Sci. Rep. 2016, 6, 27145, doi:10.1038/srep27145. [CrossRef] [PubMed]

87. Liu, Y.; Wang, F.; Wang, X.; Wang, X.; Flahaut, E.; Liu, X.; Li, Y.; Wang, X.; Xu, Y.; Shi, Y.; et al. Planar carbon nanotube-graphene hybrid films for high-performance broadband photodetectors. Nat. Commun. 2015, 6, 8589, doi:10.1038/ncomms9589. [CrossRef] [PubMed]

88. Zhang, T.-F.; Li, Z.-P.; Wang, J.-Z.; Kong, W.-Y.; Wu, G.-A.; Zheng, Y.-Z.; Zhao, Y.-W.; Yao, E.-X.; Zhuang, N.-X.; Luo, L.-B. Broadband photodetector based on carbon nanotube thin film/single layer graphene Schottky junction. Sci. Rep. 2016, 6, 38569, doi:10.1038/srep38569. [CrossRef] [PubMed]

89. Mudd, G.W.; Svatek, S.A.; Hague, L.; Makarovsky, O.; Kudrynskyi, Z.R.; Mellor, C.J.; Beton, P.H.; Eaves, L.; Novoselov, K.S.; Kovalyuk, Z.D.; et al. High broad-band photoresponsivity of mechanically formed InSe-graphene van der Waals heterostructures. Adv. Mater. 2015, 27, 3760-3766. [CrossRef] [PubMed]

90. Tan, H.; Fan, Y.; Zhou, Y.; Chen, Q.; Xu, W.; Warner, J.H. Ultrathin 2D photodetectors utilizing chemical vapor deposition grown $\mathrm{WS}_{2}$ with graphene electrodes. ACS Nano 2016, 10, 7866-7873. [CrossRef] [PubMed]

91. Wang, F.; Yin, L.; Wang, Z.; Xu, K.; Wang, F.; Shifa, T.A.; Huang, Y.; Wen, Y.; Jiang, C.; He, J. Strong electrically tunable $\mathrm{MoTe}_{2}$ /graphene van der Waals heterostructures for high-performance electronic and optoelectronic devices. Appl. Phys. Lett. 2016, 109, 193111, doi:10.1063/1.4967232. [CrossRef]

92. Zhang, W.; Chuu, C.-P.; Huang, J.-K.; Chen, C.-H.; Tsai, M.-L.; Chang, Y.-H.; Liang, C.-T.; Chen, Y.-Z.; Chueh, Y.-L.; He, J.-H.; et al. Ultrahigh-gain photodetectors based on atomically thin graphene-MoS 2 heterostructures. Sci. Rep. 2014, 4, 3826, doi:10.1038/srep03826. [CrossRef] [PubMed]

93. Britnell, L.; Ribeiro, R.M.; Eckmann, A.; Jalil, R.; Belle, B.D.; Mishchenko, A.; Kim, Y.-J.; Gorbachev, R.V.; Georgiou, T.; Morozov, S.V.; et al. Strong light-matter interactions in heterostructures of atomically thin films. Science 2013, 340, 1311-1314. [CrossRef] [PubMed]

94. Yu, W.J.; Liu, Y.; Zhou, H.; Yin, A.; Li, Z.; Huang, Y.; Duan, X. Highly efficient gate-tunable photocurrent generation in vertical heterostructures of layered materials. Nat. Nanotechnol. 2013, 8, 952-958. [CrossRef] [PubMed]

95. Massicotte, M.; Schmidt, P.; Vialla, F.; Schädler, K.G.; Reserbat-Plantey, A.; Watanabe, K.; Taniguchi, T.; Tielrooij, K.J.; Koppens, F.H.L. Picosecond photoresponse in van der Waals heterostructures. Nat. Nanotechnol. 2016, 11, 42-46. [CrossRef] [PubMed]

96. Vabbina, P.; Choudhary, N.; Chowdhury, A.-A.; Sinha, R.; Karabiyik, M.; Das, S.; Choi, W.; Pala, N. Highly sensitive wide bandwidth photodetector based on internal photoemission in CVD grown p-type $\mathrm{MoS}_{2}$ /graphene Schottky junction. ACS Appl. Mater. Interfaces 2015, 7, 15206-15213. [CrossRef] [PubMed]

97. Jeong, H.; Oh, H.M.; Bang, S.; Jeong, H.J.; An, S.-J.; Han, G.H.; Kim, H.; Yun, S.J.; Kim, K.K.; Park, J.C.; et al. Metal-insulator-semiconductor diode consisting of two-dimensional nanomaterials. Nano Lett. 2016, 16, 1858-1862. [CrossRef] [PubMed]

98. Kuiri, M.; Chakraborty, B.; Paul, A.; Das, S.; Sood, A.K.; Das, A. Enhancing photoresponsivity using $\mathrm{MoTe}_{2}$-graphene vertical heterostructures. Appl. Phys. Lett. 2016, 108, 063506, doi:10.1063/1.4941996. [CrossRef]

99. Gao, A.; Liu, E.; Long, M.; Zhou, W.; Wang, Y.; Xia, T.; Hu, W.; Wang, B.; Miao, F. Gate-tunable rectification inversion and photovoltaic detection in graphene/WSe 2 heterostructures. Appl. Phys. Lett. 2016, 108, 223501, doi:10.1063/1.4953152. [CrossRef]

100. Long, M.; Liu, E.; Wang, P.; Gao, A.; Xia, H.; Luo, W.; Wang, B.; Zeng, J.; Fu, Y.; Xu, K.; et al. Broadband photovoltaic detectors based on an atomically thin heterostructure. Nano Lett. 2016, 16, 2254-2259. [CrossRef] [PubMed] 
101. Bartolomeo, A.D. Graphene Schottky diodes: An experimental review of the rectifying graphene/semiconductor heterojunction. Phys. Rep. 2016, 606, 1-58. [CrossRef]

102. Li, X.; Zhu, H. The graphene-semiconductor Schottky junction. Phys. Today 2016, 69, 47-50. [CrossRef]

103. Li, H.; Wang, X.; Xu, J.; Zhang, Q.; Bando, Y.; Golberg, D.; Ma, Y.; Zhai, T. One-dimensional CdS nanostructures: A promising candidate for pptoelectronics. Adv. Mater. 2013, 25, 3017-3037. [CrossRef] [PubMed]

104. Meyer, J.; Khalandovsky, R.; Görrn, P.; Kahn, A. $\mathrm{MoO}_{3}$ films spin-coated from a nanoparticle suspension for efficient hole-injection in organic electronics. Adv. Mater. 2011, 23, 70-73. [CrossRef] [PubMed]

105. Zhong, J.Q.; Mao, H.Y.; Wang, R.; Lin, J.D.; Zhao, Y.B.; Zhang, J.L.; Ma, D.G.; Chen, W. Ionization potential dependent air exposure effect on the $\mathrm{MoO}_{3}$ / organic interface energy level alignment. Org. Electron. 2012, 13, 2793-2800. [CrossRef]

106. Pavesi, L.; Negro, L.D.; Mazzoleni, C.; Franzò, G.; Priolo, F. Optical gain in silicon nanocrystals. Nature 2000, 408, 440-444. [CrossRef] [PubMed]

107. Duan, Y.; Kong, J.F.; Shen, W.Z. Raman investigation of silicon nanocrystals: Quantum confinement and laser-induced thermal effects. J. Raman Spectrosc. 2012, 43, 756-760. [CrossRef]

108. Kim, S.; Choi, S.-H. Size-dependent correlation of the photoluminescence lifetime with Si suboxide states at Si nanocrystal $/ \mathrm{SiO}_{2}$ interfaces. J. Korean Phys. Soc. 2008, 52, 462-465. [CrossRef]

109. Look, D.C. Recent advances in ZnO materials and devices. Mater. Sci. Eng. B Solid State Mater. Adv. Technol. 2001, 80, 383-387. [CrossRef]

110. Özgur, Ü.; Alivov, Y.I.; Liu, C.; Teke, A.; Reshchikov, M.A.; Doğan, S.; Avrutin, A.; Cho, S.-J.; Morkoç, H. A comprehensive review of $\mathrm{ZnO}$ materials and devices. J. Appl. Phys. 2005, 98, 041301. [CrossRef]

111. Liang, S.; Sheng, H.; Liu, Y.; Huo, Z.; Lu, Y.; Shen, H.J. ZnO Schottky ultraviolet photodetectors. Cryst. Growth 2001, 225, 110-113. [CrossRef]

112. Jin, Y.; Wang, J.; Sun, B.; Blakesley, J.C.; Greenham, N.C. Solution-processed ultraviolet photodetectors based on colloidal ZnO nanoparticles. Nano Lett. 2008, 8, 1649-1653. [CrossRef] [PubMed]

113. Baeg, K.-J.; Binda, M.; Natali, D.; Caironi, M.; Noh, Y.-Y. Organic light detectors: Photodiodes and phototransistors. Adv. Mater. 2013, 25, 4267-4295. [CrossRef] [PubMed]

114. Cao, H.; He, W.; Mao, Y.; Lin, X.; Ishikawa, K.; Dickerson, J.H.; Hess, W.P. Recent progress in degradation and stabilization of organic solar cells. J. Power Sources 2014, 264, 168-183. [CrossRef]

115. AL-Busaidi, Z.; Pearson, C.; Groves, C.; Petty, M.C. Enhanced lifetime of organic photovoltaic diodes utilizing a ternary blend including an insulating polymer. Sol. Energy Mater. Sol. Cells 2017, 160, 101-106. [CrossRef]

116. Kojima, A.; Teshima, K.; Shirai, Y.; Miyasaka, T. Organometal halide perovskites as visible-light sensitizers for photovoltaic cells. J. Am. Chem. Soc. 2009, 131, 6050-6051. [CrossRef] [PubMed]

117. Etgar, L.; Gao, P.; Xue, Z.; Peng, Q.; Chandiran, A.K.; Liu, B.; Nazeeruddin, M.K.; Gratzel, M. Mesoscopic $\mathrm{CH}_{3} \mathrm{NH}_{3} \mathrm{PbI}_{3} / \mathrm{TiO}_{2}$ heterojunction solar cells. J. Am. Chem. Soc. 2012, 134, 17396-17399. [CrossRef] [PubMed]

118. Frost, J.M.; Butler, K.T.; Brivio, F.; Hendon, C.H.; Schilfgaarde, M.V.; Walsh, A. Atomistic origins of high-performance in hybrid halide perovskite solar cells. Nano Lett. 2014, 14, 2584-2590. [CrossRef] [PubMed]

119. Stranks, S.D.; Eperon, G.E.; Grancini, G.; Menelaou, C.; Alcocer, M.J.P.; Leijtens, T.; Herz, L.M.; Petrozza, A.; Snaith, H.J. Electron-hole diffusion lengths exceeding1 micrometer in an organometal trihalide perovskite absorber. Science 2013, 342, 341-344. [CrossRef] [PubMed]

120. Giorgi, G.; Fujisawa, J.I.; Segawa, H.; Yamashita, K. Small photocarrier effective masses featuring ambipolar transport in methylammonium lead iodide perovskite: A density functional analysis. J. Phys. Chem. Lett. 2013, 4, 4213-4216. [CrossRef] [PubMed]

121. Ponseca, C.S.; Savenije, T.J.; Abdellah, M.; Zheng, K.; Yartsev, A.; Pascher, T.; Harlang, T.; Chabera, P.; Pullerits, T.; Stepanov, A.; et al. Organometal halide perovskite solar cell materials rationalized: Ultrafast charge generation, high and microsecond-long balanced mobilities, and slow recombination. J. Am. Chem. Soc. 2014, 136, 5189-5192. [CrossRef] [PubMed]

122. Sun, Z.; Liu, Z.; Li, J.; Tai, G.-A.; Lau, S.P.; Yan, F. Infrared photodetectors based on CVD-grown graphene and $\mathrm{PbS}$ quantum dots with ultrahigh responsivity. Adv. Mater. 2012, 24, 5878-5883. [CrossRef] [PubMed]

123. Hu, X.; Zhang, X.; Liang, L.; Bao, J.; Li, S.; Yang, W.; Xie, Y. High-performance flexible broadband photodetector based on organolead halide perovskite. Adv. Funct. Mater. 2014, 24, 7373-7380. [CrossRef] 
124. Jariwala, D.; Sangwan, V.K.; Lauhon, L.J.; Marks, T.J.; Hersam, M.C. Carbon nanomaterials for electronics, optoelectronics, photovoltaics, and sensing. Chem. Soc. Rev. 2013, 42, 2824-2860. [CrossRef] [PubMed]

125. Dai, L.; Chang, D.W.; Baek, J.-B.; Lu, W. Carbon nanomaterials for advanced energy conversion and storage. Small 2012, 8, 1130-1166. [CrossRef] [PubMed]

126. Shearer, C.J.; Cherevan, A.; Eder, D. Application and future challenges of functional nanocarbon hybrids. Adv. Mater. 2014, 26, 2295-2318. [CrossRef] [PubMed]

127. Zhang, D.; Gan, L.; Cao, Y.; Wang, Q.; Guo, X. Understanding charge transfer at PbS-decorated graphene surfaces toward a tunable photosensor. Adv Mater. 2012, 24, 2715-2720. [CrossRef] [PubMed]

128. Popov, V.N. Carbon nanotubes: Properties and application. Mater. Sci. Eng. R 2004, 43, 61-102. [CrossRef]

129. Schall, D.; Neumaier, D.; Mohsin, M.; Chmielak, B.; Bolten, J.; Porschatis, C.; Prinzen, A.; Matheisen, C.; Kuebart, W.; Junginger, B.; et al. 50 GBit/s photodetectors based on wafer-scale graphene for integrated silicon photonic communication systems. ACS Photonics 2014, 1, 781-784. [CrossRef]

130. Eda, G.; Maier, S.A. Two-dimensional crystals: Managing light for optoelectronics. ACS Nano 2013, 7, 5660-5665. [CrossRef] [PubMed]

131. Furchi, M.M.; Polyushkin, D.K.; Pospischil, A.; Mueller, T. Mechanisms of photoconductivity in atomically thin $\mathrm{MoS}_{2}$. Nano Lett. 2014, 14, 6165-6170. [CrossRef] [PubMed]

(C) 2018 by the authors. Licensee MDPI, Basel, Switzerland. This article is an open access article distributed under the terms and conditions of the Creative Commons Attribution (CC BY) license (http:/ / creativecommons.org/licenses/by/4.0/). 